\title{
Systematic review and meta-analysis: rapid diagnostic tests versus placental histology, microscopy and PCR for malaria in pregnant women
}

Johanna H Kattenberg ${ }^{1,2^{*}}$, Eleanor A Ochodo ${ }^{1,3}$, Kimberly R Boer ${ }^{4}$, Henk DFH Schallig ${ }^{1}$, Petra F Mens ${ }^{1,2}$ and Mariska MG Leeflang ${ }^{3,4}$

\begin{abstract}
Background: During pregnancy, malaria infection with Plasmodium falciparum or Plasmodium vivax is related to adverse maternal health and poor birth outcomes. Diagnosis of malaria, during pregnancy, is complicated by the absence or low parasite densities in peripheral blood. Diagnostic methods, other than microscopy, are needed for detection of placental malaria. Therefore, the diagnostic accuracy of rapid diagnostic tests (RDTs), detecting antigen, and molecular techniques (PCR), detecting DNA, for the diagnosis of Plasmodium infections in pregnancy was systematically reviewed.
\end{abstract}

Methods: MEDLINE, EMBASE and Web of Science were searched for studies assessing the diagnostic accuracy of RDTs, PCR, microscopy of peripheral and placental blood and placental histology for the detection of malaria infection (all species) in pregnant women.

Results: The results of 49 studies were analysed in metandi (Stata), of which the majority described $P$. falciparum infections. Although both placental and peripheral blood microscopy cannot reliably replace histology as a reference standard for placental P. falciparum infection, many studies compared RDTs and PCR to these tests. The proportion of microscopy positives in placental blood (sensitivity) detected by peripheral blood microscopy, RDTs and PCR are respectively 72\% [95\% Cl 62-80], 81\% [95\% Cl 55-93] and 94\% [95\% Cl 86-98]. The proportion of placental blood microscopy negative women that were negative in peripheral blood microscopy, RDTs and PCR (specificity) are 98\% [95\% Cl 95-99], 94\% [95\% Cl 76-99] and 77\% [95\% Cl 71-82]. Based on the current data, it was not possible to determine if the false positives in RDTs and PCR are caused by sequestered parasites in the placenta that are not detected by placental microscopy.

Conclusion: The findings suggest that RDTs and PCR may have good performance characteristics to serve as alternatives for the diagnosis of malaria in pregnancy, besides any other limitations and practical considerations concerning the use of these tests. Nevertheless, more studies with placental histology as reference test are urgently required to reliably determine the accuracy of RDTs and PCR for the diagnosis of placental malaria. $P$. vivaxinfections have been neglected in diagnostic test accuracy studies of malaria in pregnancy.

Keywords: Malaria, pregnancy, malaria in pregnancy (MiP), rapid diagnostic tests (RDTs), PCR, microscopy, histology, diagnostic test accuracy, systematic review, meta-analysis

\footnotetext{
* Correspondence: E.Kattenberg@KIT.nl

${ }^{1}$ Royal Tropical Institute/Koninklijk Instituut voor de Tropen (KIT), KIT Biomedical Research, Parasitology Unit, Meibergdreef 39, 1105 AZ

Amsterdam, the Netherlands

Full list of author information is available at the end of the article
} 


\section{Background}

Malaria infection during pregnancy is a major public health problem in subtropical regions throughout the world. An estimated 125.2 million pregnancies occurred in areas with Plasmodium falciparum and/or Plasmodium vivax transmission in 2007, of which approximately 30.3 million occurred in Africa [1,2]. Of the five human malaria species, $P$. falciparum causes the most severe effects during pregnancy, and $P$. vivax is associated with maternal anaemia and low birth weight $[3,4]$. The effects of Plasmodium malariae, Plasmodium ovale and Plasmodium knowlesi infections in pregnancy are not well studied. P. falciparum infection during pregnancy is estimated to cause 10,000 maternal deaths each year and annually an estimated 75,000-200,000 infant deaths are linked to malaria in pregnancy (MiP) $[1,2,5,6]$. In low-transmission areas, $P$. falciparum infection during pregnancy usually presents as a symptomatic, severe disease that can result in death of mother and foetus. In high-transmission areas few P. falciparum infections result in fever and maternal death, but the newborn infant can be severely affected by intrauterine growth retardation and pre-term delivery [2]. Infants born after a pregnancy affected by malaria often suffer from anaemia and have an increased risk of contracting malaria themselves [2]. Furthermore, P. falciparum infection during pregnancy increases the risk of stillbirth [2]. The severe effects of $P$. falciparum and $P$. vivax malaria on pregnant women and their (unborn) infants make early detection and subsequent treatment of great importance. Even though there are control measures to prevent malaria infection during pregnancy, such as intermittent preventive treatment (IPTp) and bed nets (ITNs), diagnosis is essential in areas where there is anti-malarial or insecticide resistance. IPTp greatly reduces prevalence of malaria and severe consequences, but women are not protected throughout the entire pregnancy and can still become infected between doses or after the final dose, especially when other protective measures such as ITNs are not being used, or parasites are resistant to sulphadoxine-pyrimethamine. IPTp is mostly applied in areas where there is high malaria transmission, where women have acquired immunity and infection during the pregnancy is often asymptomatic, but not without consequences. Therefore, accurate diagnostic tools are necessary to confirm infection. Additionally, screening and subsequent treatment of women during pregnancy might be more effective than a preventive approach in areas with low levels of transmission or highly seasonal transmission $[7,8]$. Using IPTp in low transmission areas might result in a large proportion of pregnant women receiving sulphadoxinepyrimethamine unnecessarily and a strategy has been proposed to screen pregnant women at antenatal care (ANC) visits with a rapid diagnostic test (RDT) and treat women who are positive with an effective antimalarial [8]. An essential element of this strategy is good accuracy of the test and moreover it requires an affordable and quick diagnostic tool, such as an RDT.

$P$. falciparum infection in pregnant women presents differently than in non-pregnant women, where parasites are found in the circulation and can sequester to endothelial cells [9]. In pregnant women, $P$. falciparum malaria parasites express a different antigen variant (VAR2CSA) than in non-pregnant women, allowing them to sequester in the placenta and this is known as placental malaria [10]. Hence, in pregnant women peripheral parasitaemia can be absent or below the detection limit of microscopy $[11,12]$.

While microscopic examination of blood slides is considered the 'gold standard' for diagnosis in non-pregnancy related malaria, accurate detection of parasite infection in the placenta requires examination of histological sections of fixed placental tissue [13-15]. An alternative is to examine placental blood with microscopy $[11,12,15]$. Placental histology and microscopic examination of placental blood can only be performed after delivery, when the placenta is available for examination. Since the detection of malaria parasites in the placenta is not possible during pregnancy, there is at this moment no other alternative than to detect the infection in peripheral blood.

There are alternatives to microscopic examination to test the peripheral blood though, such as rapid diagnostic tests (RDTs), which have the advantage of being quick and easy in remote settings. Depending on the manufacturer, the quality of the RDT in terms of accuracy and stability can be high $[16,17]$. RDTs are based on the detection of parasite antigens in the blood by specific monoclonal antibodies. RDTs for malaria detect one or more of the following antigens: Histidine Rich Protein 2 (HRP2), Plasmodium Lactate Dehydrogenase (pLDH) or Aldolase. In a recent systematic review comparing diagnostic accuracy of RDTs for uncomplicated $P$. falciparum infection, it was reported that HRP2based RDTs have better sensitivity than pLDH-based tests, although specificity is better for pLDH-based tests [18]. In general, RDTs detecting HRP2 are most commonly used, because they are less expensive, more stable across a wider temperature range and have a lower detection threshold than pLDH-based tests $[19,20]$. HRP2-based tests, however, detect only P. falciparum, and antigenic variation of this antigen may cause false negative results [21]. The HRP2 antigen is excreted from the infected red blood cell, which can be beneficial for the diagnosis of placental malaria, as the antigen can 
be detected in the circulation even when the parasite is sequestered in the placenta [22].

Other alternatives for malaria diagnosis are DNA/ RNA-based detection techniques, of which the polymerase chain reaction (PCR) is the most widely used $[23,24]$. PCR is considered to have the most sensitive detection level of parasites (for both regular peripheral malaria and placental malaria), but requires highly trained staff and specialized equipment, which are not always available in resource-poor settings $[11,12,15]$.

Both PCR and RDTs are reported to have a higher sensitivity for placental malaria in peripheral and placental blood than microscopy, but are considered not to be as accurate as placental histopathology, however, evidence for this conclusion has not been summarized [11]. Besides accuracy there are many other reasons for choosing to use a certain type of diagnostic test, such as affordability, number of tests to be performed in a certain time, equipment, trained staff, etc., that depend on the setting and location in which the test will be used. Without a sufficient level of accuracy, however, there is no justification of using a certain test, even if it is practical and affordable and perhaps the only possibility in a certain situation. Therefore, the aim of the present study is to investigate the published diagnostic accuracy of RDTs and PCR for the diagnosis of malaria infection in pregnant women compared to a reference standard. These tests should at least have a better sensitivity and specificity than peripheral microscopy. Different consequences of the results will be discussed.

\section{Methods \\ Eligible studies}

Eligible studies were primary studies that assessed the diagnostic accuracy of RDTs, PCR, and microscopy of peripheral- or placental blood or placental histology for the detection of malaria in pregnant women. Studies included pregnant women (any age, gestation and parity) in malaria endemic regions (all human-infecting Plasmodium species). Studies that compared selected healthy controls to confirmed malaria patients (case-control) were not eligible for inclusion, because they tend to give an over-estimation of the sensitivity and specificity of the test under evaluation [25]. RDTs detecting any type of antigen (HRP2, pLDH, Aldolase), in any format (lateral flow cassette, dipstick, card etc.) and from any manufacturer were eligible as well as molecular diagnostic tests (PCR) in any format using Plasmodium DNA and/ or RNA amplification.

\section{Definitions}

Malaria infection of red blood cells in pregnant women can be found in both the peripheral and placental circulation and sequestered in the placenta and other organs or tissue. Placental malaria is defined as the presence of malaria parasites in placental tissue or blood in this study. Peripheral malaria infection is defined as the presence of malaria parasites in the circulation (peripheral blood). Both types of infection often occur at the same time and when it is not clear which of the two it is or specification is not desired, it is called malaria in pregnancy $(\mathrm{MiP})$.

\section{Reference test: histology}

Histological examination of a stained biopsy from the maternal side of the placenta is considered the gold standard for diagnosis of placental malaria. The biopsy is examined for the presence of malaria parasites and pigment in the placental tissue. Placental histology slides can be classified in active (parasites in the placenta), active chronic (parasites and pigment in placenta), past (only pigment in placenta) and no infection (no parasites or pigment in placenta) [13,14]. For the $2 \times 2$ tables both active and active-chronic infections were considered as positive for placental malaria and past and no infections as negative. Even though past infection is a clinically relevant outcome, and indicates that the participant has been infected during the pregnancy, for the purpose of comparing diagnostics only the current state of infection is of interest. In one study, past infection was considered as positive and the results were not presented for each class separately [26]. This study was not included in the meta-analysis, because it was the only study comparing RDT to histology. In two other studies, it was not specified if past infection was considered positive or negative. These studies were included in the meta-analysis and may be a source of bias $[27,28]$.

\section{Reference tests: placental and peripheral blood microscopy}

Histology is not available or practical in all situations, and not suitable for certain study designs. Instead, microscopic slide investigation of placental or peripheral blood is used as reference test. Slides are made from placental blood from the inter-villous space of the placenta, which can be collected in many different ways, for example, by aspiration with a syringe or as impression smear of placental tissue. For peripheral blood microscopy, venous or capillary blood is collected and thick and thin smears are made. Slides from blood of both sources are dried, fixed (thin smear), stained and examined microscopically for the presence of malaria parasites. Although peripheral parasitaemia during pregnancy has been related to placental infection at delivery, microscopy of peripheral blood indicates a different situation than histology; i.e. it detects parasites in the circulation (with or without placental infection) [29]. In order to gain more insight into the value of these 
different reference standards, they were evaluated against placental histology.

\section{Search strategy}

Electronic databases were searched with the provided search terms. To avoid missing studies, the search terms were kept broad. The searches were performed in September 2009 in duplicate and updated in October 2010 and June 2011.

Medline (through Pubmed) was searched with ("malaria"[MeSH Terms] OR Plasmodium [All Fields] OR "malaria"[All Fields]) AND ("pregnancy"[MeSH Terms] OR "pregnancy"[All Fields] OR pregnan"[ti]).

EMBASE (through OVID) was searched with search terms: ('malaria'/exp or 'malaria'.mp. or ('plasmodium'/ exp or 'plasmo"'mp.)) and ('pregnancy'/exp or 'pregnan"'.mp.) and 'paludisme'.

In Web of Science the following search term was used: TS $=(($ malaria OR plasmo*) AND pregnan*).

The WHO library database (through e-library OPAC on WHO website) was searched with three terms 'malaria AND pregnancy', 'paludisme AND enceinte' and 'paludisme AND grossesse'.

Reference lists of the selected studies, narrative and systematic reviews and primary studies on malaria in pregnancy were manually checked for other relevant studies. Conference programmes and abstracts of recent conferences on malaria were consulted for recently conducted studies and the websites of the Roll Back Malaria programme, WHO and TDR were visited and searched for reports or publications [30-32].

\section{Selection of studies}

A primary selection, based on title and abstract (compiled in reference manager [33]), was performed independently by two authors (JK and EO). Duplicate studies and studies that were not using diagnostic tests for malaria in pregnant women were removed. All studies considered relevant by at least one of the two authors were selected. If the full paper could not be retrieved online or through the central catalogue of Dutch academic libraries (NCC), and if the contact details could be retrieved, the authors were approached. In case the full paper was obtained, the same two authors independently assessed the study for inclusion, based on eligibility (described earlier) and the availability of data to derive $2 \times 2$ tables. Disagreements were resolved by discussion or by consulting a third author (PM or ML). Study information and fulfilment to the inclusion criteria was collected using an Epidata entry form [34]. If data for RDT evaluations were only partially reported, authors were contacted to provide the data if the contact details were available.

\section{Data extraction and management}

Two authors (JK and EO) collected the data from included studies independently on forms prepared in separate Access databases (Microsoft 2003). Information about the study (title, authors, journal, etc.), study population and study design was collected, as well as descriptions of reference and index tests and data for $2 \times 2$ tables. The database was accompanied by a background document that explained how each item in the database should be interpreted and entered. After entry of all studies, the two databases were compared, and disagreements were resolved by discussion between the two data-collectors or if necessary with a third author (PM). Most disagreements in the two data sets turned out to be data entry errors.

Methodological quality was assessed using the QUADAS tool [35]. A study was considered to have a high risk of partial verification bias if more than $10 \%$ of the patients who received the index test did not receive verification of their true disease state, and the selection of patients to receive the reference standard was not random. A study was considered to have a high risk of differential verification bias if more than $10 \%$ of patients received verification with a different reference standard. Studies with a high risk of partial or differential verification bias were not included in the meta-analysis. A few additional items were added to the QUADAS tool that can be important for RDT accuracy. These items are: 'Has care been taken to store the tests at recommended circumstances (time, temperature, humidity)?' and 'Was the staff that executed the reference standard trained to use this test?'. In several studies more than two tests were compared, and multiple $2 \times 2$ tables could be extracted. Several quality items were considered for the separate test comparisons within one study.

\section{Statistical analysis and data synthesis}

For each $2 \times 2$ table, the estimates of sensitivity and specificity and their $95 \%$ confidence interval were plotted in forest plots and receiver operating characteristic (ROC) space in Review Manager [36]. For the meta-analysis, metandi was used in Stata $[37,38]$. To perform metandi, a minimum of four $2 \times 2$ tables is required.

\section{Investigation of sources of heterogeneity}

Diagnostic accuracy studies are expected to show considerable heterogeneity and the models used are by default random effects models, taking into account the between study variation as well as chance variation [39]. To further investigate the sources of heterogeneity, subgroup analyses was performed rather than including covariates in the meta-regression models, because metandi is not capable of including covariates in the 
analyses. The type of antigen (HRP2 or pLDH or Aldolase or in combination) detected by the RDT was investigated as a source of heterogeneity. For other supposed sources that might affect the accuracy of the RDTs, such as malaria species, gravidity, anti-malarial treatment and RDT brand, insufficient data was reported to determine if these issues affected accuracy.

\section{Results}

\section{Results of the search}

The searches in MEDLINE, EMBASE and Web of Science (WOS) retrieved 3,069, 3,167 and 2,249 studies, respectively. After removing duplicates, 169 studies were selected based on title and abstract. Additional searches retrieved another 23 studies. From these 192 studies, 131 were excluded for several reasons: full text paper could not be retrieved ( $\mathrm{n}=12$ ), no pregnant women described $(\mathrm{n}=18)$, insufficient data collected or provided for $2 \times 2$ tables $(n=54)$, narrative reviews or editorial or letter $(\mathrm{n}=16)$, description of the same population as another study ( $\mathrm{n}=13)$, no formal evaluation against an eligible reference standard $(\mathrm{n}=14)$ and various other reasons $(n=4)$ (Figure 1$)$.

Additional file 1 lists the characteristics of the 61 included studies in the review $[7,26,27,29,40-94]$. Studies were performed between 1914 and 2009, and included approximately 45,000 women during pregnancy or at delivery. Most studies were conducted in sub-Saharan Africa $(\mathrm{n}=52)$. Only four were conducted in South-East Asia (three in India, one in Thailand), and two in Yemen and one each in, Colombia, Panama and Papua New Guinea. Corresponding with the geographical locations, the majority of studies described P. falciparum infections (53 of 61 reported P. falciparum infection; in eight studies species were not specified). Only six studies reported $P$. vivax infections. P. malariae $(\mathrm{n}=16)$ and $P$. ovale $(\mathrm{n}=6)$ infections are rarely seen in the placenta, and were more often reported in peripheral blood as a mixed infection with $P$. falciparum and only in a small portion of patients (Additional file 1). There are not enough studies to perform subgroup analysis for the different species to determine if there is a difference in test accuracy to detect different malaria species, and most importantly between $P$. vivax and $P$. falciparum. Only 13 of 61 studies used placental histology.

\section{Methodological quality of included studies}

The results of the quality assessment are presented in Figure 2. Most studies included a representative patient spectrum, but in two studies they included either only patients that were positive in a reference test or those that were negative [52,59]. Additionally, one study included patients that were positive in the index test and 30 negatives, but not randomly chosen [70]. Selection criteria were not

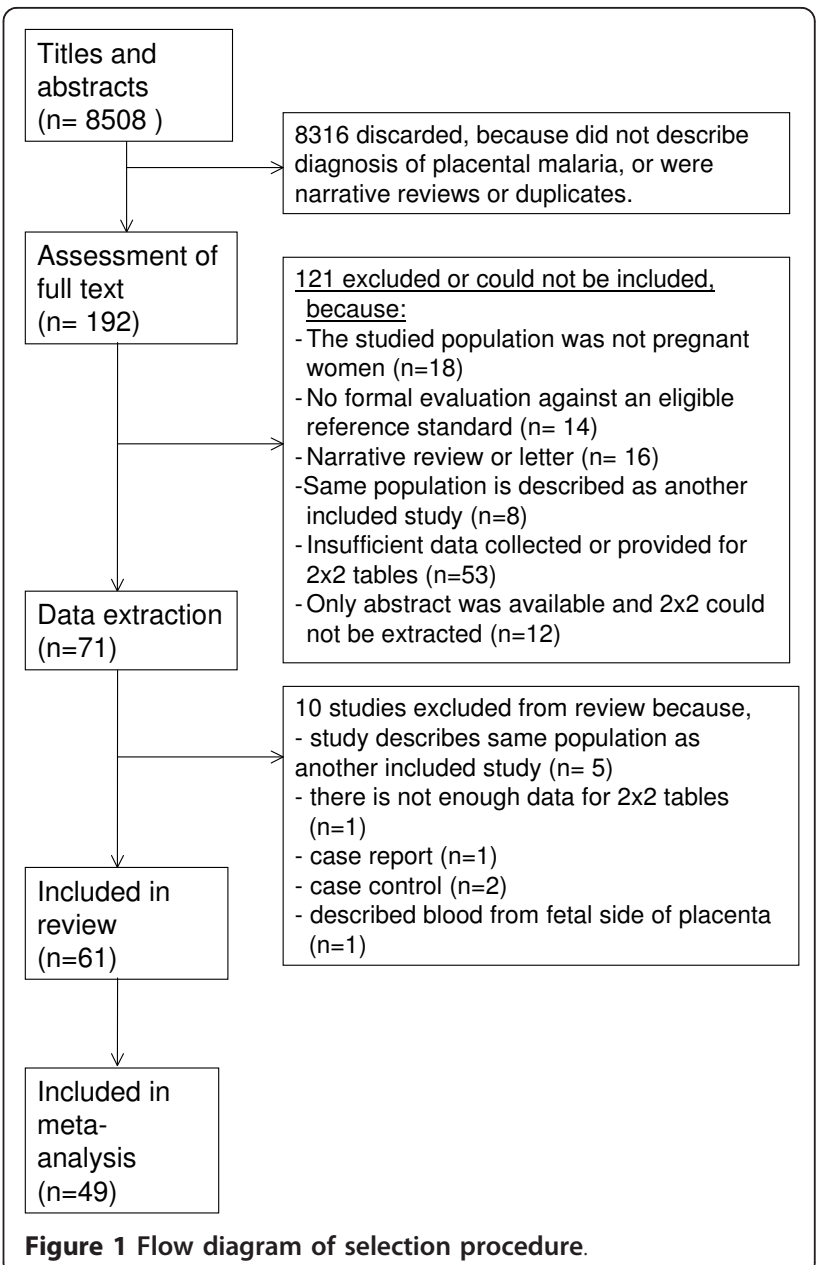

sufficiently described in 16 studies [27,28,40,43,45-47,55, $62,68,69,72,76,80,81,87]$. Very little was reported on storage conditions of the tests and whether or not staff was trained for the reference or index tests. In about a quarter of the studies $(\mathrm{n}=15)$ withdrawals were not explained $[27,42,48,49,51,53,56,61,62,64,69,73,74,80,84]$.

Partial verification was a problem in four test comparisons (in four different studies), and these studies were removed from the meta-analysis $[61,67,80,83]$. Differential verification was not a problem in any of the comparisons. For most of the tests $(n=83)$ the execution of the test was described sufficiently, but in only a few comparisons ( $\mathrm{n}=17$ for index test; $\mathrm{n}=30$ for the reference test) did the authors clearly mention that the interpretation of the tests was blinded, and only in a small number $(n=30)$ of the studies they reported that the reproducibility of the index test was tested.

\section{Findings}

Of the 61 studies included in the review, only 49 could be evaluated in the meta-analyses. These 49 studies are presented in the forest plots (Figures 3, 4, 5, 6 and 7). Some 


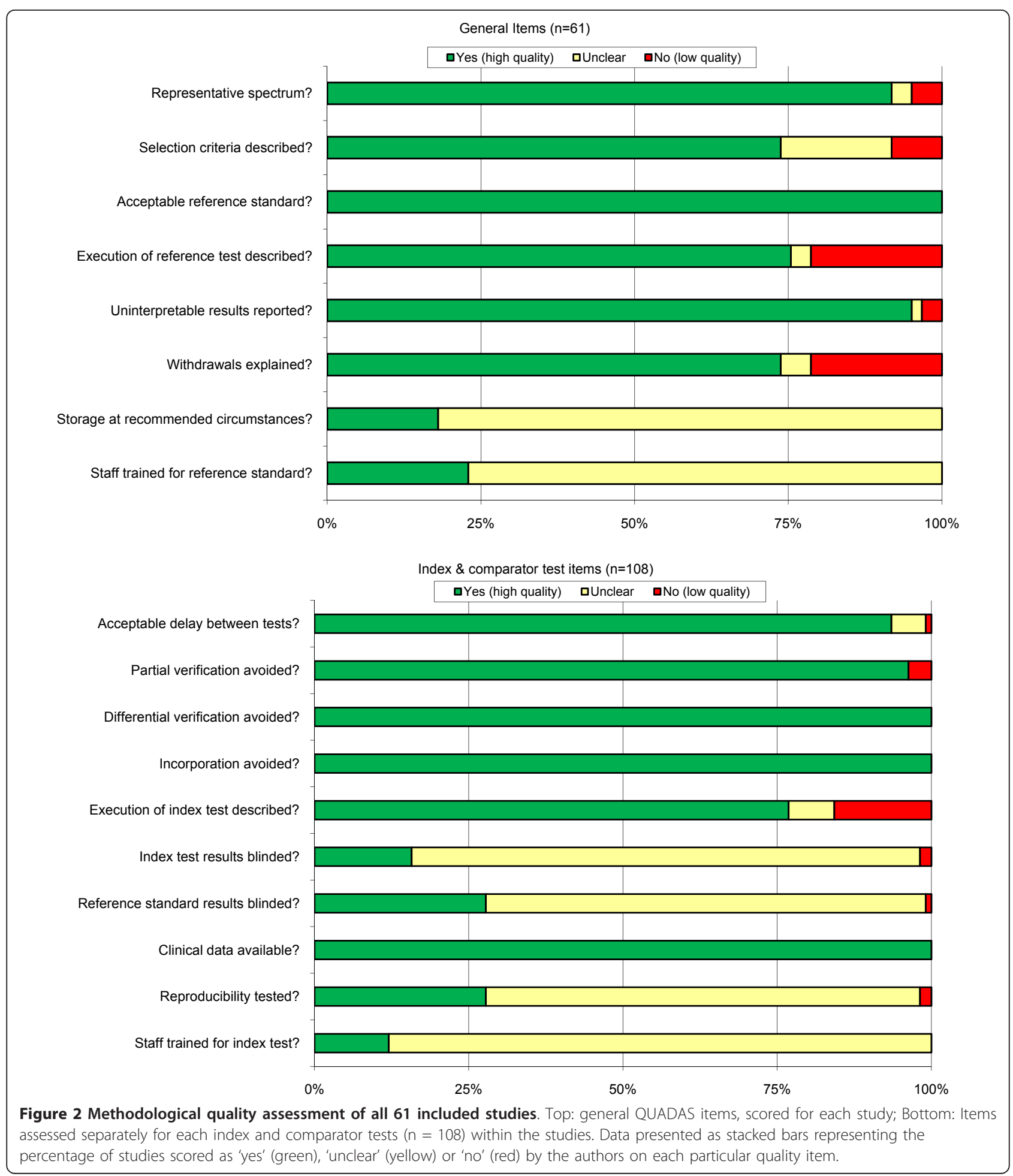

of the studies were not included in the meta-analysis, not enough studies to perform meta-analysis of these particular test comparisons were described and these studies are listed in Additional file 2 with the retrieved sensitivity and specificity. A substantial number of studies had to be excluded from final analyses, because there was not enough data to fill the $2 \times 2$ tables $(n=4)$ or because they suffered from partial verification bias $(n=2)$, or the $2 \times 2$ tables were only available for a subset of the patients $(\mathrm{n}=$ 3 ). In separate cases the studies were excluded, because 
Placental blood microscopy

$\begin{array}{lrrrrrr}\text { Study } & \text { TP } & \text { FP } & \text { FN } & \text { TN } & \text { Sensitivity } & \text { Specificity } \\ \text { Anchang-Kimbi 2009 } & 66 & 12 & 54 & 174 & 0.55[0.46,0.64] & 0.94[0.89,0.97] \\ \text { McGready 2004 } & 7 & 5 & 24 & 146 & 0.23[0.10,0.41] & 0.97[0.92,0.99] \\ \text { *Menendez 2008 } & 77 & 10 & 354 & 404 & 0.18[0.14,0.22] & 0.98[0.96,0.99] \\ \quad \text { Okoko 2002 } & 114 & 2 & 46 & 151 & 0.71[0.64,0.78] & 0.99[0.95,1.00] \\ \text { Rogerson 2003 } & 73 & 5 & 40 & 346 & 0.65[0.55,0.73] & 0.99[0.97,1.00] \\ \text { *Sarr 2006 } & 40 & 17 & 7 & 37 & 0.85[0.72,0.94] & 0.69[0.54,0.80] \\ \quad \text { Shulman 2001 } & 94 & 19 & 102 & 673 & 0.48[0.41,0.55] & 0.97[0.96,0.98]\end{array}$

Peripheral blood microscopy

Study
*Anchang-Kimbi 2009
Bako 2009
Ismail 2000
Leopardi 1996
McGready 2004
Meuris 1993
Nyirjesy 1993
Rogerson 2003
*Sarr 2006
Shulman 2001
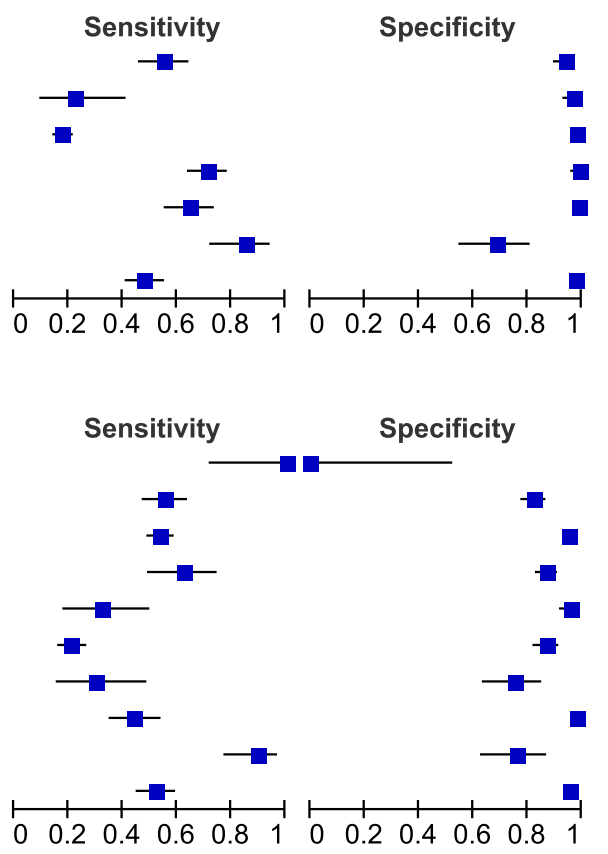

Figure 3 Forest plots of sensitivity and specificity of microscopy of peripheral and placental blood with placental histology as reference test. The squares represent the calculated specificity and sensitivity of one test within a study; the black line is the $95 \%$ confidence interval. Tests with $a^{*}$ in front were excluded from the meta-analysis, because of high risk of bias or complete data was not available.

the subgroups ended up being too small $(n=1)$, there was a too long a time delay between the tests $(n=1)$, or they used only matched negative cases $(n=1)$. The exact reasons for exclusion of each study are explained in the sections below. Only the most correctly-conducted studies were used to determine the accuracy and, therefore, the studies described above were excluded. The effect of exclusion of these studies was systematically examined, and in most cases the summary estimates were essentially unchanged. When the summary estimates were different when these tests were included in the analysis, this is discussed in the sections below.

The median prevalence of malaria (mostly P. falciparum) found by placental histology was $33.2 \%$ (range 17.2-52.5\%). This median prevalence was retrieved from all included studies using histology and these studies were published between 1993 and 2009. These studies all included regular pregnant women presenting for delivery or recruited at ANC and followed till delivery $[7,26,28,42,51,55,67,69,73,86]$.

\section{Peripheral and placental blood microscopy vs reference standard histology}

In order to determine whether tests other than placental histology can be used as substitute reference standards, the accuracies of microscopy of placental and peripheral blood were evaluated. Seven studies evaluated microscopy of placental blood with placental histology as reference test, but one was excluded from the meta-analysis because there was a high risk of partial verification bias (Figure 3) [61,70]. Another study was excluded from the meta-analysis because it included women that were RDT positive and matched negative women [70]. The summary estimates of the five included studies in the meta-analysis for sensitivity and specificity were $54 \%$ [40-67 CI] and 97\% [95-98 CI], respectively (Table 1 and Figure 8). Since the pathology of $P$. vivax infections during pregnancy has not been fully elucidated, the sensitivity and specificity of placental tests might be different for $P$. vivax infections compared to $P$. falciparum. If the study with $P$. vivax infections was excluded from the meta-analysis, there was a slight increase in sensitivity (60\% [50-69 CI]) [7].

From the ten studies that evaluated peripheral blood microscopy against placental histology, two were excluded from the meta-analysis. One study did not report false- and true negatives [42], and one study included women that were RDT positive and matched negative women [70] (Figure 3). The summary estimates for sensitivity and specificity of the included studies 


\begin{tabular}{|c|c|c|c|c|c|c|c|c|}
\hline Study & TP & FP & FN & TN & Sensitivity & Specificity & Sensitivity & Specificity \\
\hline Adegnika 2006 & 12 & 1 & 2 & 130 & $0.86[0.57,0.98]$ & $0.99[0.96,1.00]$ & & \\
\hline Albiti 2010 & 6 & 0 & 26 & 868 & $0.19[0.07,0.36]$ & $1.00[1.00,1.00]$ & & - \\
\hline Archibald 1958 & 58 & 7 & 8 & 411 & $0.88[0.78,0.95]$ & $0.98[0.97,0.99]$ & & च \\
\hline Bassiouny 2005 & 11 & 6 & 0 & 259 & $1.00[0.72,1.00]$ & $0.98[0.95,0.99]$ & & 口 \\
\hline Clark 1915 & 8 & 0 & 11 & 381 & $0.42[0.20,0.67]$ & $1.00[0.99,1.00]$ & & च \\
\hline *Cottrell 2005 & 41 & 53 & 54 & 722 & $0.43[0.33,0.54]$ & $0.93[0.91,0.95]$ & & - \\
\hline Desowitz 1992 & 5 & 1 & 11 & 66 & $0.31[0.11,0.59]$ & $0.99[0.92,1.00]$ & & $\rightarrow$ \\
\hline *Diallo 1981 & 16 & 8 & 11 & 0 & $0.59[0.39,0.78]$ & $0.00[0.00,0.37]$ & & \\
\hline Falade 2010 & 109 & 16 & 19 & 839 & $0.85[0.78,0.91]$ & $0.98[0.97,0.99]$ & & - \\
\hline Kalanda 2006 & 140 & 154 & 91 & 1019 & $0.61[0.54,0.67]$ & $0.87[0.85,0.89]$ & & - \\
\hline *Kassberger 2002 & 37 & 0 & 0 & 0 & $1.00[0.91,1.00]$ & Not estimable & & \\
\hline Kasumba 2000 & 36 & 10 & 0 & 491 & $1.00[0.90,1.00]$ & $0.98[0.96,0.99]$ & & $\mathbf{\square}$ \\
\hline Leke 1999 & 176 & 14 & 46 & 841 & $0.79[0.73,0.84]$ & $0.98[0.97,0.99]$ & & - \\
\hline Lukuka 2006 & 24 & 13 & 5 & 154 & $0.83[0.64,0.94]$ & $0.92[0.87,0.96]$ & & $\square$ \\
\hline Mankhambo 2002 & 38 & 3 & 35 & 433 & $0.52[0.40,0.64]$ & $0.99[0.98,1.00]$ & & - \\
\hline *McGready 2004 & 12 & 0 & 0 & 0 & $1.00[0.74,1.00]$ & Not estimable & & \\
\hline Minang 2004 & 14 & 13 & 20 & 63 & $0.41[0.25,0.59]$ & $0.83[0.73,0.91]$ & & $\rightarrow-$ \\
\hline Mockenhaupt 2006 & 148 & 11 & 145 & 535 & $0.51[0.45,0.56]$ & $0.98[0.96,0.99]$ & & घ \\
\hline Mokuolu 2009 & 182 & 137 & 85 & 1471 & $0.68[0.62,0.74]$ & $0.91[0.90,0.93]$ & & - \\
\hline Mukhtar 2006 & 15 & 4 & 0 & 81 & $1.00[0.78,1.00]$ & $0.95[0.88,0.99]$ & & $\rightarrow$ \\
\hline Peel 1948 & 174 & 44 & 24 & 125 & $0.88[0.83,0.92]$ & $0.74[0.67,0.80]$ & & $\rightarrow$ \\
\hline Piola 2010 & 6 & 0 & 4 & 294 & $0.60[0.26,0.88]$ & $1.00[0.99,1.00]$ & & घ \\
\hline Rogerson 2003 & 49 & 9 & 29 & 376 & $0.63[0.51,0.74]$ & $0.98[0.96,0.99]$ & & - \\
\hline Schwetz 1934 & 32 & 6 & 5 & 7 & $0.86[0.71,0.95]$ & $0.54[0.25,0.81]$ & & \\
\hline Singer 2004 & 148 & 88 & 33 & 530 & $0.82[0.75,0.87]$ & $0.86[0.83,0.88]$ & & - \\
\hline Sowunmi 1996 & 22 & 1 & 5 & 44 & $0.81[0.62,0.94]$ & $0.98[0.88,1.00]$ & & $\rightarrow$ \\
\hline Sullivan 2000 & 22 & 5 & 35 & 95 & $0.39[0.26,0.52]$ & $0.95[0.89,0.98]$ & & $\rightarrow$ \\
\hline Tako 2005 & 275 & 25 & 105 & 1490 & $0.72[0.68,0.77]$ & $0.98[0.98,0.99]$ & $\mathrm{E}$ & - \\
\hline van Dongen 1982 & 13 & 0 & 15 & 127 & $0.46[0.28,0.66]$ & $1.00[0.97,1.00]$ & & - \\
\hline van Eijk 2002 & 307 & 73 & 95 & 1954 & $0.76[0.72,0.80]$ & $0.96[0.95,0.97]$ & & G \\
\hline
\end{tabular}

Figure 4 Forest plots of sensitivity and specificity of peripheral blood microscopy with placental blood microscopy as reference test. The squares represent the calculated specificity and sensitivity of one test within a study; the black line is the $95 \%$ confidence interval. Tests with $a^{*}$ in front were excluded from the meta-analysis, because of high risk of bias or complete data was not available.

were 44\% [34-54 CI] and 92\% [86-95 CI] respectively (Table 1). If the case-control study was included, the summary sensitivity would have been 49\% [35-64 CI]. When performing the meta-analysis with $P$. falciparum studies only ( $P$. vivax study [7] removed) the sensitivity and specificity hardly changed (45\% [34-56 CI] and 91\% [84-95 CI] respectively).

In Figure 8 the summary ROC curve presents the summary estimates for placental blood and peripheral blood microscopy compared to histology. Placental blood microscopy had a slightly higher sensitivity and specificity than peripheral microscopy (Figure 8 ). There is, however, quite some overlap in the $95 \%$ confidence regions of the summary estimates, meaning that the true accuracy of the tests might be more alike (Figure $8)$. Both tests showed much variation in their sensitivity, ranging from $23 \%$ to $71 \%$ for placental blood and from $21 \%$ to $62 \%$ for peripheral blood, respectively. Neither of the two tests, however, reaches a summary sensitivity of at least $90 \%$, and for peripheral blood microscopy the upper limit of the confidence interval is much lower than $90 \%$ specificity.

\section{Peripheral blood microscopy vs reference test placental blood microscopy}

Many studies $(n=30)$ evaluated peripheral blood microscopy with placental blood microscopy as a reference, but four studies were excluded from the meta-analysis. Two of these four studies presented incomplete data for the $2 \times 2$ table [7,52], another only presented the $2 \times 2$ table for a subset of the patients (those with newborns with malaria) [48] and in the last study the delay between the sampling for the two tests is too long [29] (Figure 4). Sensitivity and specificity from the included studies are plotted in a summary ROC plot for peripheral blood microscopy with placental blood microscopy as reference test (Figure 9). The sensitivity varied from $19 \%$ to $100 \%$ with a summary estimate of $72 \%$ [62-80\% CI] (Table 1 and Figure 9). The 
RDT peripheral blood

$\begin{array}{lrrrrrr}\text { Study } & \text { TP } & \text { FP } & \text { FN } & \text { TN } & \text { Sensitivity } & \text { Specificity } \\ \text { * Kassberger 2002 } & 35 & 0 & 2 & 0 & 0.95[0.82,0.99] & \text { Not estimable } \\ \text { Leke 1999 } & 57 & 6 & 7 & 111 & 0.89[0.79,0.95] & 0.95[0.89,0.98] \\ \text { ** Mankhambo 2002 } & 28 & 9 & 45 & 89 & 0.38[0.27,0.50] & 0.91[0.83,0.96] \\ \text { Mockenhaupt 2006 } & 228 & 58 & 65 & 488 & 0.78[0.73,0.82] & 0.89[0.86,0.92] \\ \text { Singer 2004 } & 146 & 208 & 7 & 329 & 0.95[0.91,0.98] & 0.61[0.57,0.65]\end{array}$

RDT placental blood

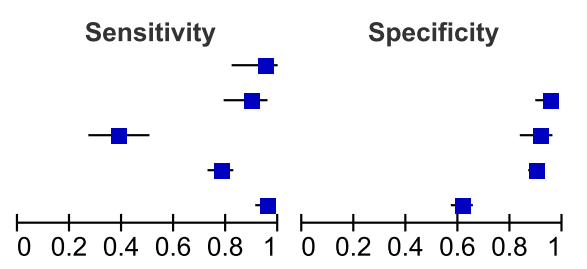

Study

*** Carmona-Fonseca 2010

** Hamer 2009

** Hamer 2009

*Kassberger 2002

* Sarr 2006

Singer 2004

Singh 2005

Singh 2005
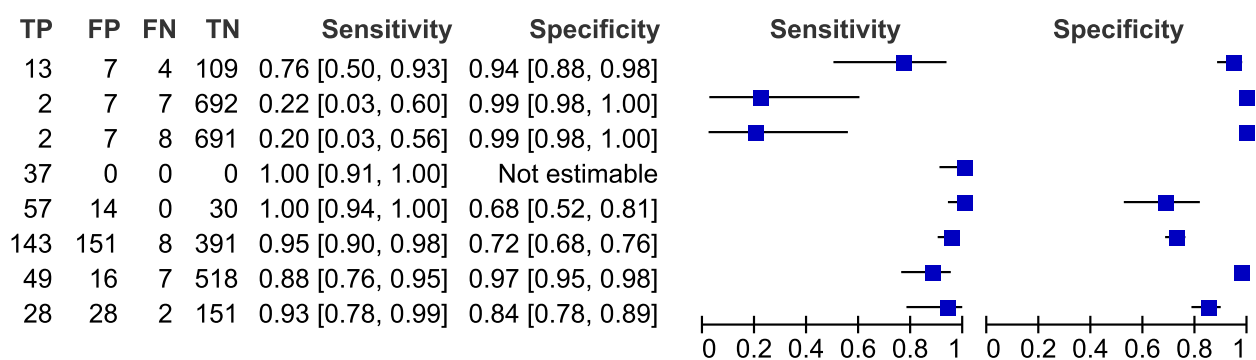

Figure 5 Forest plots of sensitivity and specificity of RDTs with microscopy of placental blood as reference test. The squares represent the calculated specificity and sensitivity of one test within a study; the black line is the 95\% confidence interval. Tests with a * in front were excluded from the meta-analysis, because of high risk of bias or complete data was not available; with ** means that a pLDH-based RDT has been used; ${ }^{* * *}$ means that a HRP2-Aldolase-based RDT has been used.

specificity, varied from $54 \%$ to $100 \%$, and the summary estimate was 98\% [95-99\% CI] (Table 1 and Figure 9). There is one study where a $P$. vivax infection is observed in peripheral blood and not in placental blood, but the summary estimates are not different if this study is excluded from meta-analysis (sensitivity 73\% [63-81 CI] and specificity 98\% [95-99 CI]) [47].
RDT and PCR vs reference test histology

The preferred reference standard for placental malaria remains histology, but unfortunately, only one study was included evaluating an RDT (HRP2-Aldolase) with peripheral blood against histology (sensitivity 57\% [41-73 CI] and specificity 90\% [80-96 CI]) [27]. One other study evaluated an RDT with placental blood to

PCR peripheral blood

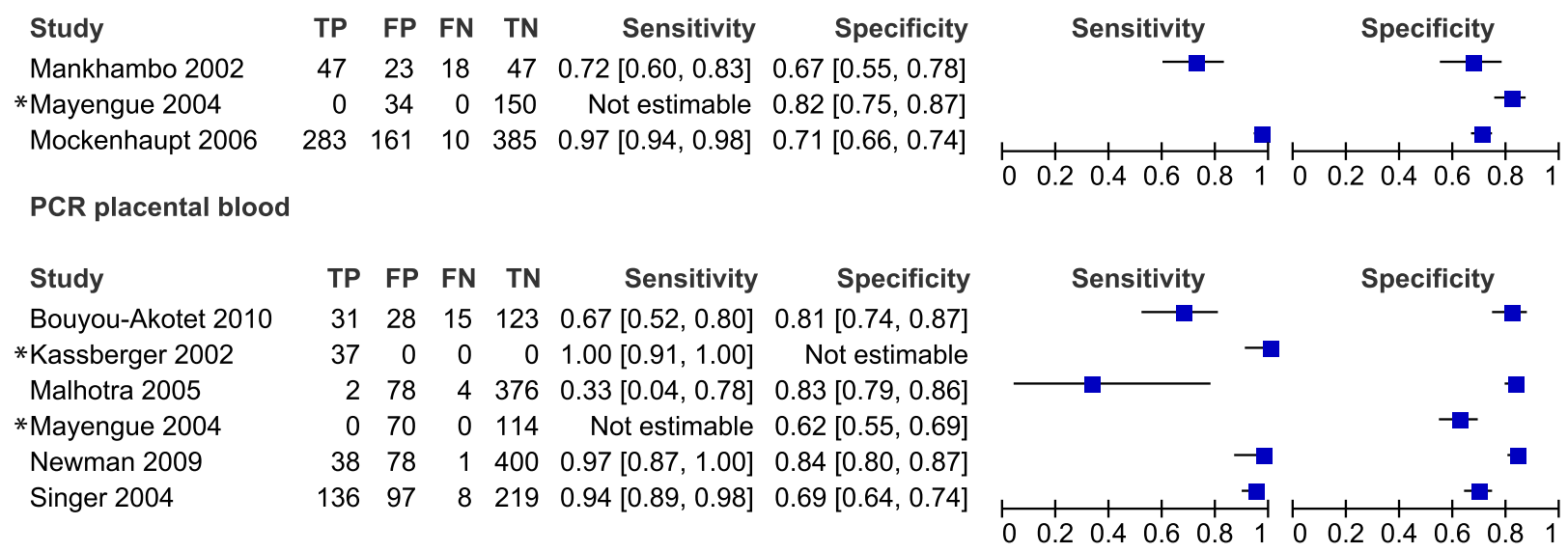

Figure 6 Forest plots of sensitivity and specificity of PCR with microscopy of placental blood as reference test. The squares represent the calculated specificity and sensitivity of one test within a study; the black line is the $95 \%$ confidence interval. Tests with a * in front were excluded from the meta-analysis, because of high risk of bias or complete data was not available. 


\begin{tabular}{|lrrrrrr}
\hline RDT with peripheral blood & & & & & & \\
Study & TP & FP & FN & TN & Sensitivity & Specificity \\
*** Carmona-Fonseca 2010 & 19 & 5 & 5 & 114 & $0.79[0.58,0.93]$ & $0.96[0.90,0.99]$ \\
** Hamer 2009 & 14 & 12 & 29 & 3040 & $0.33[0.19,0.49]$ & $1.00[0.99,1.00]$ \\
*Kassberger 2002 & 35 & 0 & 2 & 0 & $0.95[0.82,0.99]$ & Not estimable \\
Kilian 1999 & 42 & 12 & 4 & 66 & $0.91[0.79,0.98]$ & $0.85[0.75,0.92]$ \\
Leke 1999 & 51 & 12 & 3 & 115 & $0.94[0.85,0.99]$ & $0.91[0.84,0.95]$ \\
* Mankhambo 2002 & 29 & 8 & 12 & 122 & $0.71[0.54,0.84]$ & $0.94[0.88,0.97]$ \\
Mockenhaupt 2006 & 148 & 138 & 11 & 542 & $0.93[0.88,0.96]$ & $0.80[0.76,0.83]$ \\
Singer 2004 & 196 & 160 & 8 & 326 & $0.96[0.92,0.98]$ & $0.67[0.63,0.71]$ \\
*Tagbor 2008 & 1187 & 94 & 44 & 554 & $0.96[0.95,0.97]$ & $0.85[0.83,0.88]$ \\
**VanderJagt 2005 & 3 & 4 & 17 & 244 & $0.15[0.03,0.38]$ & $0.98[0.96,1.00]$ \\
& 3 & & & & &
\end{tabular}

PCR with peripheral blood

$\begin{array}{lrrrrrr}\text { Study } & \text { TP } & \text { FP } & \text { FN } & \text { TN } & \text { Sensitivity } & \text { Specificity } \\ \text { *Adam 2005 } & 0 & 40 & 0 & 85 & \text { Not estimable } & 0.68[0.59,0.76] \\ \text { Bouyou-Akotet 2010 } & 22 & 34 & 3 & 142 & 0.88[0.69,0.97] & 0.81[0.74,0.86] \\ \text { Malhotra 2005 } & 36 & 164 & 10 & 318 & 0.78[0.64,0.89] & 0.66[0.62,0.70] \\ \text { Mankhambo 2002 } & 34 & 36 & 2 & 63 & 0.94[0.81,0.99] & 0.64[0.53,0.73] \\ \text { *Mayengue 2004 } & 0 & 34 & 0 & 150 & \text { Not estimable } & 0.82[0.75,0.87] \\ \text { Mayor 2009 } & 15 & 51 & 0 & 218 & 1.00[0.78,1.00] & 0.81[0.76,0.86] \\ \text { Mockenhaupt 2000 } & 172 & 164 & 0 & 194 & 1.00[0.98,1.00] & 0.54[0.49,0.59] \\ \text { Mockenhaupt 2006 } & 158 & 286 & 1 & 394 & 0.99[0.97,1.00] & 0.58[0.54,0.62] \\ \text { Omer 2011 } & 214 & 257 & 5 & 360 & 0.98[0.95,0.99] & 0.58[0.54,0.62] \\ \text { Rantala 2010 } & 10 & 41 & 4 & 420 & 0.71[0.42,0.92] & 0.91[0.88,0.94] \\ \text { Saute 2002 } & 71 & 36 & 4 & 70 & 0.95[0.87,0.99] & 0.66[0.56,0.75] \\ \text { Singer 2004 } & 183 & 92 & 4 & 184 & 0.98[0.95,0.99] & 0.67[0.61,0.72] \\ \text { Taylor 2010 } & 74 & 35 & 102 & 1057 & 0.42[0.35,0.50] & 0.97[0.96,0.98] \\ \text { *VanderJagt 2005 } & 18 & 4 & 2 & 0 & 0.90[0.68,0.99] & 0.00[0.00,0.60]\end{array}$
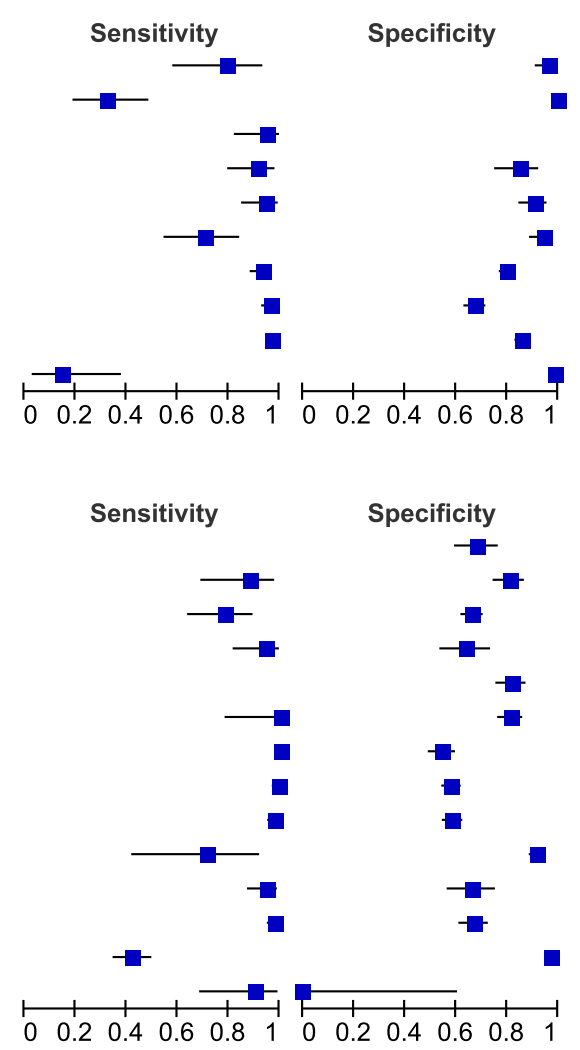

Figure 7 Forest plots of sensitivity and specificity of RDTs and PCR with microscopy of peripheral blood as reference test. The squares represent the calculated specificity and sensitivity of one test within a study; the black line is the $95 \%$ confidence interval. Tests with a * in front were excluded from the meta-analysis, because of high risk of bias or complete data was not available; with ** means that a pLDH-based RDT has been used; *** means that a HRP2-Aldolase-based RDT has been used.

histology (sensitivity 100\% [92-100 CI] and specificity 56\% [41-69 CI]) [70]. No studies evaluated PCR against histology. Too few studies were collected for meta-analysis and therefore summary sensitivities and specificities of RDT and PCR and microscopy could not be compared.

\section{RDT and PCR vs reference test placental blood microscopy}

As an alternative, some studies used microscopy of placental blood as a reference standard. Five studies compared RDT with peripheral blood to placental blood microscopy, and eight compared RDT with placental blood (Figure 5). Two studies were case-control studies, and were excluded from the meta-analysis $[58,70]$. One other study had incomplete $2 \times 2$ tables and the two 2 $\times 2$ tables from this study were therefore excluded from the analysis [52]. This leaves two pLDH tests, one HRP2-Aldolase and six HRP2 tests with sensitivities varying from $78 \%$ to $95 \%$ for peripheral blood and $20 \%$ to $95 \%$ for placental blood. Not enough studies were available to pool the $2 \times 2$ tables RDTs of peripheral blood separately, but when RDTs of both peripheral as placental blood are pooled together, the summary sensitivity is $81 \%$ [62-92 CI] and summary specificity is $94 \%$ [76-99 CI] (Table 1 and Figure 9). If RDT of placental blood is pooled separately, similar sensitivity and specificity are found (Table 1 ).

Similarly, the $2 \times 2$ tables of PCR of peripheral and placental blood compared to placental blood microscopy can be pooled and analysed together. The $2 \times 2$ tables of two studies are not complete; therefore they were not included in the meta-analysis (Figure 6)[52,59]. Summary sensitivity (86\% [65-95 CI]) is similar to RDT, but summary specificity $(77 \%$ [71-82 CI]) is lower (Table 1 and Figure 9).

Compared to peripheral microscopy, RDTs and PCR have better sensitivity than when compared to placental blood microscopy as reference standard (Figure 9). RDTs and PCR, however, do have lower specificity, but 
Table 1 Summary of findings

What is the diagnostic accuracy of microscopy of peripheral and placental blood to correctly identify histologically confirmed placental malaria (PM)?

\begin{tabular}{|c|c|c|c|c|c|}
\hline Population & \multicolumn{5}{|c|}{ Pregnant women } \\
\hline Settings & \multicolumn{5}{|c|}{ At delivery where both placental and peripheral material is available; mostly $P$. falciparum infections } \\
\hline Index test & \multicolumn{5}{|c|}{ Microscopic examination of placental or peripheral blood slide } \\
\hline Reference Test & \multicolumn{5}{|c|}{ Histological examination of placental biopsies } \\
\hline Type of test & $\begin{array}{l}\text { Effect } \\
{[95 \% \mathrm{Cl}]}\end{array}$ & $\begin{array}{l}\text { Participants } \\
\text { (studies) }\end{array}$ & $\begin{array}{l}\text { Median } \\
\text { prevalence } \\
\text { (range) }\end{array}$ & Implications of results & Quality and comments \\
\hline $\begin{array}{l}\text { Microscopy of } \\
\text { placental } \\
\text { blood }\end{array}$ & $\begin{array}{l}\text { Sensitivity } \\
54 \% \\
{[40-67]} \\
\text { Specificity } \\
97 \% \\
{[95-98]}\end{array}$ & $\begin{array}{l}2153 \\
(5)\end{array}$ & $\begin{array}{l}24.4 \% \\
(18.4-35.5)\end{array}$ & $\begin{array}{l}\text { With a prevalence of } 25 \%, 25 \text { out of } 100 \\
\text { pregnant women will develop PM; } 12 \text { and } 14 \\
\text { patients will be missed by placental and } \\
\text { peripheral microscopy. }\end{array}$ & $\begin{array}{l}\text { Representative patient spectrum; uncertain if } \\
\text { all tests blinded; withdrawals poorly } \\
\text { Reported. }\end{array}$ \\
\hline $\begin{array}{l}\text { Microscopy of } \\
\text { peripheral } \\
\text { blood }\end{array}$ & $\begin{array}{l}\text { Sensitivity } \\
44 \% \\
{[34-54]} \\
\text { Specificity } \\
92 \% \\
{[86-95]}\end{array}$ & $\begin{array}{l}4044 \\
(8)\end{array}$ & $\begin{array}{l}28.6 \% \\
(17.2-52.5)\end{array}$ & $\begin{array}{l}\text { With a prevalence of } 25 \%, 6 \text { patients will be } \\
\text { false positive in peripheral microscopy, but } \\
\text { treatment is not harmful and can act as } \\
\text { prophylaxis during the rest of the pregnancy. }\end{array}$ & $\begin{array}{l}\text { Representative patient spectrum; uncertain if } \\
\text { all tests blinded; withdrawals poorly } \\
\text { reported; } 1 \text { study did not report selection } \\
\text { criteri; } 1 \text { did not report the execution of the } \\
\text { reference test; risk of verification bias in } \\
\text { study. }\end{array}$ \\
\hline \multicolumn{6}{|c|}{ What is the diagnostic accuracy of RDTs and PCR to correctly identify PM confirmed by microscopy of placental blood? } \\
\hline Population & \multicolumn{5}{|c|}{ Pregnant women } \\
\hline Settings & \multicolumn{5}{|c|}{ At delivery where both placental- and peripheral blood is available; mostly $P$. falciparum infections } \\
\hline Index test & \multicolumn{5}{|c|}{ RDT or PCR with peripheral or placental blood } \\
\hline Reference Test & \multicolumn{5}{|c|}{ Microscopic examination of placental blood slide } \\
\hline $\begin{array}{l}\text { Type of test/ } \\
\text { subgroups }\end{array}$ & $\begin{array}{l}\text { Effect } \\
{[95 \% \mathrm{Cl}]}\end{array}$ & $\begin{array}{l}\text { Participants } \\
\text { (studies) }\end{array}$ & $\begin{array}{l}\text { Median } \\
\text { prevalence } \\
\text { (range) }\end{array}$ & Implications of results & Quality and comments \\
\hline $\begin{array}{l}\text { Microscopy of } \\
\text { peripheral } \\
\text { blood }\end{array}$ & $\begin{array}{l}\text { Sensitivity } \\
72 \% \\
{[62-80]} \\
\text { Specificity } \\
98 \% \\
{[95-99]}\end{array}$ & $\begin{array}{l}16609 \\
(26)\end{array}$ & $\begin{array}{l}15.9 \% \\
(3.3-74.0)\end{array}$ & $\begin{array}{l}\text { Of } 16 \text { of } 100 \text { patients positive in placental } \\
\text { blood, } 4 \text { would be missed in peripheral blood } \\
\text { by microscopy. }\end{array}$ & $\begin{array}{l}\text { Representative patient spectrum; } 4 \text { did not } \\
\text { describe selection criteria; execution of } \\
\text { index/reference test not reported in } 13 \text { tests }\end{array}$ \\
\hline
\end{tabular}

RDT of placental and peripheral blood

\begin{tabular}{|c|c|c|c|}
\hline $\begin{array}{l}\text { Peripheral and } \\
\text { placental } \\
\text { blood pooled } \\
\text { together }\end{array}$ & $\begin{array}{l}\text { Sensitivity } \\
81 \% \\
{[62-92]} \\
\text { Specificity } \\
94 \% \\
{[76-99]}\end{array}$ & $\begin{array}{l}3141 \\
\text { (5) }\end{array}$ & $\begin{array}{l}16.2 \% \\
(2.4-11 \\
34.9)\end{array}$ \\
\hline $\begin{array}{l}\text { only placental } \\
\text { Blood }\end{array}$ & $\begin{array}{l}\text { Sensitivity } \\
76 \% \\
{[44-92]} \\
\text { Specificity } \\
95 \% \\
{[87-99]}\end{array}$ & $\begin{array}{l}2124 \\
(4)\end{array}$ & $\begin{array}{l}11.20 \% \\
(2.4-22.6)\end{array}$ \\
\hline
\end{tabular}

PCR of placental and peripheral blood

all types of Sensitivity $2608 \quad 18.5 \% \quad$ Of 18 of 100 patients that test positive in

PCR $\quad 86 \% \quad$ (6) (1.7-34.9)

[65-95]

Specificity

$77 \%$

[71-82]
Representative patient spectrum; uncertain if all tests blinded; withdrawals poorly reported; 1 study did not report selection criteri; 1 did not report the execution of the reference test; risk of verification bias in study. 
Table 1 Summary of findings (Continued)

\begin{tabular}{|c|c|c|c|c|c|}
\hline $\begin{array}{l}\text { Index test } \\
\text { Reference Test }\end{array}$ & $\begin{array}{l}\text { RDT or PCF } \\
\text { microscopi }\end{array}$ & $\begin{array}{l}\text { with periphe } \\
\text { examination }\end{array}$ & $\begin{array}{l}\text { al blood } \\
\text { of peripheral }\end{array}$ & blood slide & \\
\hline $\begin{array}{l}\text { Type of test/ } \\
\text { subgroups }\end{array}$ & $\begin{array}{l}\text { Effect } \\
{[95 \% \mathrm{Cl}]}\end{array}$ & $\begin{array}{l}\text { Participants } \\
\text { (studies) }\end{array}$ & $\begin{array}{l}\text { Median } \\
\text { prevalence } \\
\text { (range) }\end{array}$ & Implications of results & Quality and comments \\
\hline \multicolumn{6}{|c|}{ RDT of peripheral blood } \\
\hline $\begin{array}{l}\text { all types } \\
\text { (pLDH and } \\
\text { HRP2) }\end{array}$ & $\begin{array}{l}\text { Sensitivity } \\
81 \% \\
{[55-93]} \\
\text { Specificity } \\
94 \% \\
{[82-98]}\end{array}$ & $\begin{array}{l}5340 \\
(7)\end{array}$ & $\begin{array}{l}17.60 \% \\
(1.3-51.3)\end{array}$ & $\begin{array}{l}\text { Of } 18 \text { of } 100 \text { patients positive in peripheral } \\
\text { blood microscopy, } 3 \text { would be missed in any } \\
\text { type RDT. Of } 28 \text { of } 100 \text { patients positive in } \\
\text { peripheral blood microscopy, } 2 \text { patients } \\
\text { would be missed in HRP2 RDTs. }\end{array}$ & $\begin{array}{l}\text { Representative patient spectrum; uncertain if } \\
\text { all tests blinded; withdrawals and } \\
\text { uninterpretable results poorly reported; test } \\
\text { execution not reported in } 3 / 7 \text { tests; } 1 \text { study } \\
\text { did not report selection criteria. }\end{array}$ \\
\hline $\begin{array}{l}\text { only HRP2 } \\
\text { based }\end{array}$ & $\begin{array}{l}\text { Sensitivity } \\
94 \% \\
{[91-96]} \\
\text { Specificity } \\
81 \% \\
{[71-88]}\end{array}$ & 1834(4) & $\begin{array}{l}28.10 \% \\
(17.6-51.3)\end{array}$ & $\begin{array}{l}\text { With a prevalence of } 28 \%, 14 \text { patients will be } \\
\text { false positive with HRP2 RDTs compared to } \\
\text { peripheral blood microscopy. }\end{array}$ & \\
\hline \multicolumn{6}{|c|}{ PCR of peripheral blood } \\
\hline $\begin{array}{l}\text { all types of } \\
\text { PCR }\end{array}$ & $\begin{array}{l}\text { Sensitivity } \\
94 \% \\
{[86-84]}\end{array}$ & $\begin{array}{l}5741 \\
(11)\end{array}$ & $\begin{array}{l}19.0 \% \\
(5.3-51.3)\end{array}$ & $\begin{array}{l}\text { Of } 19 \text { of } 100 \text { patients that test positive in } \\
\text { peripheral blood microscopy, only } 1 \text { would be } \\
\text { missed by PCR, but } 20 \text { would be false positive } \\
\text { compared to peripheral blood microscopy. }\end{array}$ & $\begin{array}{l}\text { Representative patient spectrum; uncertain if } \\
\text { all tests blinded; withdrawals and } \\
\text { uninterpretable results poorly reported; }\end{array}$ \\
\hline
\end{tabular}

based on the available data, it is not possible to conclude if these are indeed false positives, or infections that are missed by placental blood microscopy yet detected by RDT or PCR.

\section{RDT and PCR vs reference test peripheral blood microscopy}

Although microscopy of peripheral blood is the least appropriate reference test for placental malaria as determined in a previous section, it has often been used as a reference test in practice. Many studies have been performed during pregnancy and not at delivery, which explains why peripheral blood microscopy is used. Ten studies compared RDTs (two pLDH and one HRP2Aldolase and seven HRP2-based tests) to microscopy of peripheral blood and 14 compared PCR to peripheral microscopy. For both PCR and RDT, three studies each were excluded from meta-analysis because of incomplete data [40,52,59], case control [58] or high risk of verification bias [80,83] (only for PCR in [80]). Sensitivity and specificity is presented between quotation marks in the section below to underline the fact that peripheral blood microscopy is not an appropriate reference test for placental malaria.

Analysis was performed for HRP2-based RDTs separately (Figure 7 ). Too few studies were retrieved in order to perform subgroup analysis on pLDH based RDTs, and therefore a sensitivity analysis was performed by comparing all RDT studies with a subgroup of HRP2-based RDTs. The summary estimate of "sensitivity" was higher for the HRP2 subgroup (94\% [91-96 CI]) compared to the overall analysis for all RDT types (81\% [55-93 CI]). For the summary estimate of the "specificity", however, the opposite was observed: $81 \%$ [71-88 $\mathrm{CI}$ ] for the HRP2 subgroup and 94\% [82-98 CI] for all type RDTs (Table 1 and Figure 10). Although the difference is not significant, it might indicate that, at least for placental malaria, there is a difference in accuracy between the different RDT types (Figure 10).

In studies where PCR was compared to microscopy of peripheral blood, a quite good "sensitivity" was found (71\% - 100\%) except for one outlier (42\%), but a low "specificity" was observed, varying from 54\% to $97 \%$ (Figure 7). This resulted in the summary estimates of "sensitivity" and "specificity" of 94\% [86-98 CI] and 75\% [63-84 CI] respectively (Table 1 and Figure 10).

\section{Discussion}

To estimate the accuracy of RDTs for diagnosing malaria infection in pregnant women, the results of 49 studies were analysed. Few studies exist that fully evaluate microscopy, RDTs and PCR against the gold standard, placental histology, and each other. This makes it difficult to directly compare the accuracies of the different tests, and therefore currently no reliable data about the accuracy of RDTs and PCR for the detection of placental malaria is available. The present study shows that microscopy of both placental and peripheral blood do not detect many placental infections that are identified by histology (sensitivities of $54 \%$ and $44 \%$ ) and cannot reliably replace histology as a reference standard for placental $P$. falciparum infection. Despite these limitations 


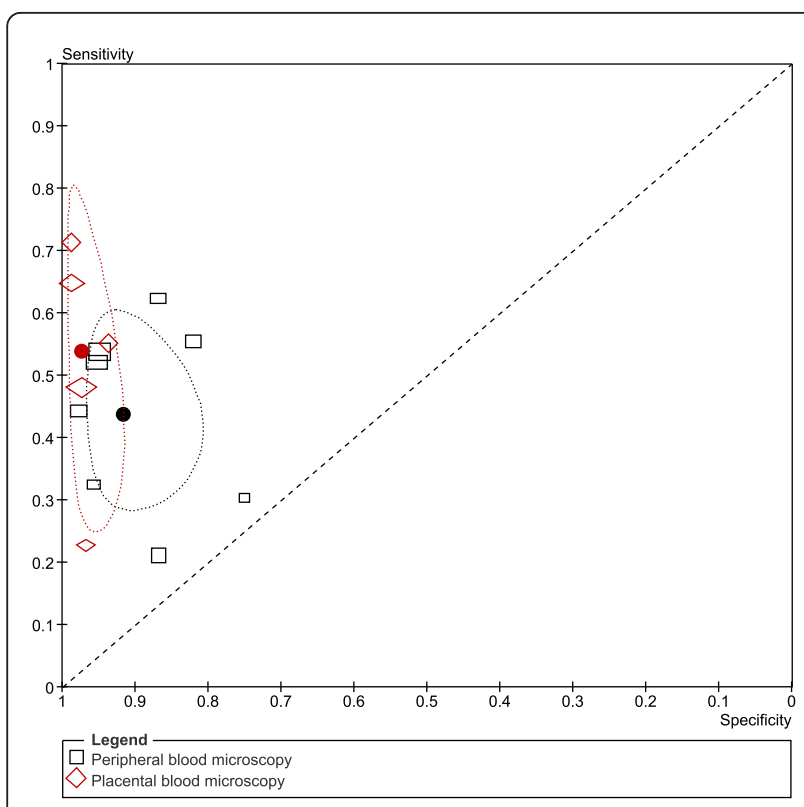

Figure 8 Summary ROC plot of sensitivity and specificity of peripheral and placental blood microscopy with placental histology as a reference test. The sensitivity of a test is plotted against 1-specificity, allowing comparison of both parameters at the same time for multiple tests. The rectangles and diamonds represent individual studies and size of the rectangles/diamonds is proportional to the number of patients included in the study. The thick round spots are the summary estimates of sensitivity and specificity and the dotted ellipses around the spots represent the 95\% confidence intervals around the summary estimates. Black: peripheral blood microscopy; Red: placental blood microscopy. The reference test used to determine the plotted accuracies in this figure is placental histology.

RDTs, especially HRP2-based tests, appear to have reasonable accuracy compared to microscopy. The World Health Organization (WHO) together with the Foundation for Innovative New Diagnostics (FIND) have performed extensive testing of many RDT devices and there is a great need to compare the best tests from that evaluation with histology, microscopy and PCR in pregnant women [20].

When using placental microscopy as a reference test, PCR has the best sensitivity, followed by RDT and both have higher sensitivity than peripheral microscopy. Peripheral microscopy, however, has the highest specificity, followed closely by RDT. Based on these results, RDTs seem a good alternative for diagnosis of placental malaria. For the determination of the accuracy of RDT and PCR compared to placental blood microscopy, however, tests performed on both peripheral and placental blood were pooled. This might have introduced bias, since the starting material is not the same, and therefore, the accuracy might be different. There were, however, too few studies performed on peripheral blood

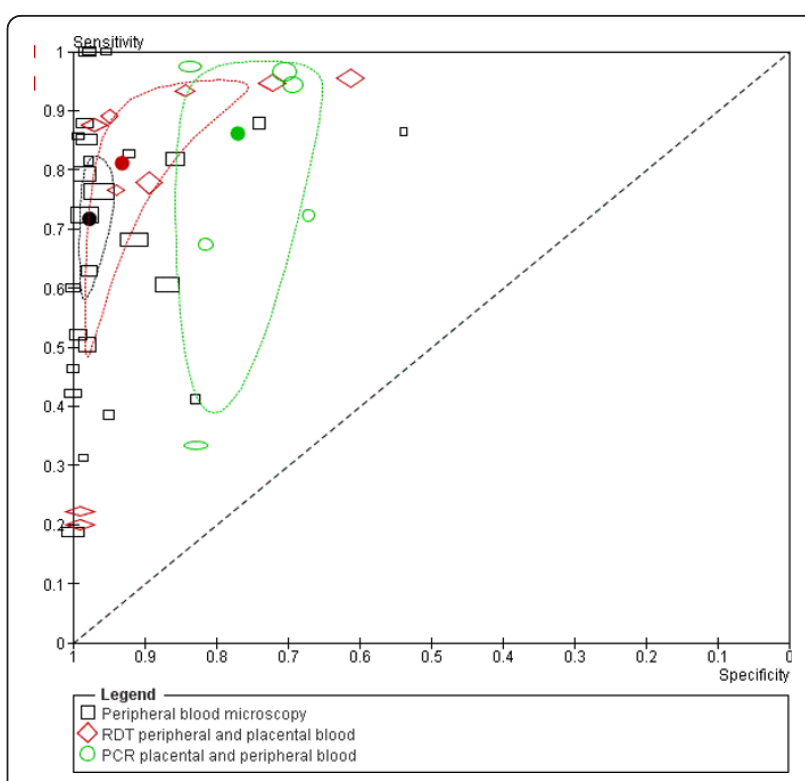

Figure 9 Summary ROC plot of sensitivity and specificity of RDT and PCR of peripheral and placental blood and microscopy of peripheral blood with placental blood microscopy as reference test. The sensitivity of a certain test is plotted against 1-specificity, allowing comparison of both parameters at the same time for multiple tests. The squares, diamonds and open circles represent individual studies and size of the rectangles/diamonds/circles is proportional to the number of patients included in the study. The thick round spots are the summary estimates of sensitivity and specificity and the dotted ellipses around the spots represent the 95\% confidence intervals around the summary estimates. Black (squares): RDTs (detecting HRP2 or pLDH or HRP2-Aldolase). Red (diamonds): peripheral blood microscopy. Green (circles): PCR; The reference test used to determine the plotted accuracies in this figure is placental blood microscopy.

alone to perform meta-analysis. The pooled summary sensitivities and specificities are not that different from the summary values of these tests using placental blood, but this may be due to the fact that these tests are a large proportion of the pooled analysis.

Compared to the imperfect reference standard peripheral microscopy, the proportion of microscopy positives detected by any RDT ("sensitivity") was 81\% [51-95 CI]. The proportion microscopy negatives, with a negative RDT ("specificity"), was 94\% [76-99 CI]. As the RDTs seem to miss patients that are positive in microscopy, this is not very reassuring for the value of RDTs for the diagnosis of malaria in pregnant women. Nevertheless, HRP2-based RDTs might have adequate sensitivity (94\% [91-96 CI]).

The results in this study suggest that the proportion of microscopy positives detected by HRP2-based RDTs compared to peripheral microscopy is higher than for pLDH-based RDTs. The proportion microscopy negatives with a negative RDT, however, is lower for HRP2 
RDTs compared to pLDH RDTs. This pattern is similar to the results of a meta-analysis of RDTs for uncomplicated malaria, and the sensitivity of HRP2-based RDTs for pregnant women $(94 \%$ [91-96 CI]) is very similar to that for uncomplicated malaria (95\% [93-96 CI]) [18]. The specificity compared to peripheral microscopy for HRP2-based RDTs for pregnant women (81\% [71-88 $\mathrm{CI}]$ ), however, is much lower than for uncomplicated malaria (95\% [93-99 CI]). A possible explanation for this observation is that peripheral microscopy is not a suitable reference test for placental malaria and does not detect all placental infections, whereas the HRP2 RDTs might be able to detect these infections, resulting in a lower specificity when compared to peripheral microscopy. This is strengthened by the specificity of HRP2 RDTs (90\% [84-95 CI]) compared to placental blood microscopy, which detects more placental infections

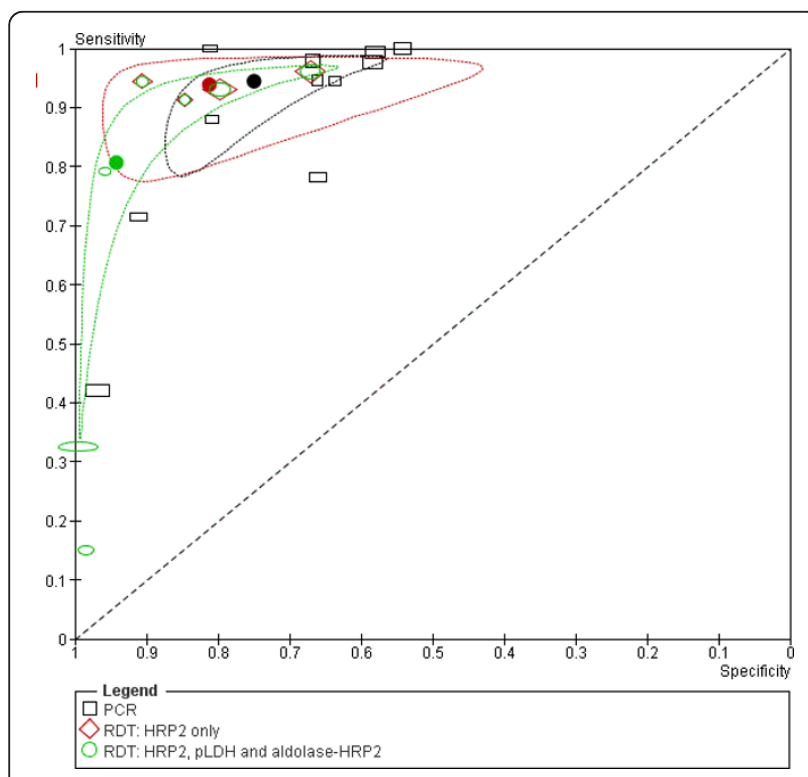

Figure 10 Summary ROC plot of sensitivity and specificity of RDT and PCR with peripheral blood with peripheral blood microscopy as reference test. The sensitivity of a certain test is plotted against 1-specificity, allowing comparison of both parameters at the same time for multiple tests. The rectangles, diamonds and circles represent individual studies and size of the rectangles/diamonds/circles is proportional to the number of patients included in the study. The thick round spots are the summary estimates of sensitivity and specificity for the different test types and the dotted ellipses around the spots represent the 95\% confidence intervals around the summary estimates. Black (rectangles): PCR studies; Red (diamonds): studies with HRP2 based RDTs only; Green (circles): studies with RDTs, including both HRP2, pLDH and HRP2-Aldolase detecting tests. The reference test used to determine the plotted accuracies in this figure is placental histology. The inclusion of the pLDH and Aldolase-HRP2 based RDTs

dramatically changes the summary estimate and confidence interval (green) compared to HRP2 tests alone (red), the sensitivity is much lower with the $\mathrm{pLDH}$ tests. than peripheral microscopy. Direct comparisons of HRP2 RDTs with histology are needed to confirm this.

For PCR, the proportion of microscopy positives detected ("sensitivity") was 98\% [91-99 CI] and the proportion microscopy negatives, with a negative PCR ("specificity"), was 65\% [59-72 CI]. PCR may seem to miss fewer patients with peripheral P. falciparum parasites than an RDT, but does indicate a number of women without parasites detected by microscopy as having malaria. Whether these are cases that were missed by microscopy or whether these were false positive PCR results, resulting in low specificity, needs to be further investigated.

The sensitivity and specificity of tests vary with parasite density, and many included studies report lower sensitivities at lower parasite densities (two studies for PCR and RDT; seven for RDTs; four for microscopy). This factor is a particular challenge for malaria infections during pregnancy in both high and low transmission settings, especially for multigravid women who are often reported to have lower parasite densities. Of the included studies, 13 report higher parasite densities in peripheral and/or placental blood for primi- and/or secundigravidae. In high transmission areas, women have acquired immunity during their life, and although they might have substantial placental sequestration (especially in primi- and secundigravidae), they can have a lower amount of parasites in the circulation by clearance of infected red blood cells by the immune system. In low transmission areas, women have low or no immunity and women can get sick at initially low parasite densities. Therefore it is very important for the diagnosis of malaria in pregnant women that the test has sufficient accuracy at lower parasite densities, and low parasite density might partially explain the poor performance of pLDH RDTs.

In a previous report, prevalence of placental malaria estimated by different tests was compared within each study [11]. However, even if the prevalence detected by one test is higher than the prevalence detected with the other test, it does not necessarily mean that the same cases are detected. Additionally, in this way it is not clear whether the positives found by each test are true positives or false positives. Nevertheless, the conclusions of that report and this review are broadly similar. Histology found a higher prevalence than placental blood microscopy and placental blood microscopy in turn found a higher prevalence than peripheral microscopy in four out of six studies. In both peripheral and placental blood, in nearly all studies, higher prevalence was found using PCR than using RDT and higher prevalence was found using RDT than using microscopy. No studies compared prevalence estimated by RDT and PCR to prevalence found by histology. 
The results presented in this review are mainly applicable to sub-Saharan Africa, as $85 \%$ of the included studies were conducted in that area. It is surprising that only a few studies were available evaluating diagnostics in the Asian-Pacific region, considering that most pregnancies at risk in the world are located in this region [6]. In line with this observation, most studies described $P$. falciparum infections, and only six studies reported $P$. vivax infections. Meta-analysis was based on studies of which the majority described $P$. falciparum infections and studies with $P$. vivax infections had little influence on the outcome. Therefore, conclusions in this review are mainly applicable to $P$. falciparum infections. Due to the potential pathological differences between $P$. falciparum and $P$. vivax infection in pregnancy a difference in diagnostic accuracy of the various tests is expected between the species and more studies should aim at evaluating diagnostics in $P$. vivax-infected pregnant women in the future. Too few studies with $P$. vivax infections were included in the meta-analysis to be able to determine if there is a difference in accuracy.

The use of PCR for diagnosis of (placental) malaria remains a matter of discussion, especially in the submicroscopic cases, because it is difficult to determine what the PCR is detecting. It is very sensitive in detecting parasite nucleic acids, but it is unclear if this is a residual from a non-viable sequestered parasite, or a viable parasite or gametocyte. Additionally, there is some discussion whether these low parasite levels detected by PCR are clinically relevant. Several studies have tried to address this issue by researching the association of a positive (submicroscopic) PCR result and outcome measures such as anaemia, low birth weight and premature delivery. A systematic review has been conducted to summarize this data and concluded that the frequency of anaemia is significantly lower in uninfected women compared to women with a submicroscopic infection, although the risk is lower than with microscopic infections, and a similar pattern is found for low birth weight [95]. The review on the effects of submicroscopic infections did not include three studies that have been described in the current study $[60,90,93]$. One of these three studies described a significantly increased risk of anaemia with submicroscopic infections compared to PCR- and microscopy negative women, as well [60]. One of the other studies describes that submicroscopic infection was predictive of low birth weight in HIV positive, but not HIV negative women [90]. More comparisons with histology might shed more light on this issue and show that a significant proportion of the peripheral submicroscopic infections, are in fact placental infections. As mentioned before, pregnant women often have low parasite densities, and tests should have good sensitivity at these low densities; PCR techniques often have better sensitivities at low parasite densities than RDTs and microscopy.

\section{Conclusions}

Currently, there is no reliable data about the accuracy of RDTs and PCR for the detection of placental malaria. This is because the studies done so far used invalid reference standards. Before a firm conclusion can be drawn about whether RDTs or PCR can be used to detect placental malaria, these tests should be evaluated against histological examination of the placenta. Direct comparisons of RDTs and PCR against histology versus peripheral microscopy against histology are needed to decide whether RDTs or PCR have better accuracy for placental malaria than (currently used) peripheral microscopy.

\section{Additional material}

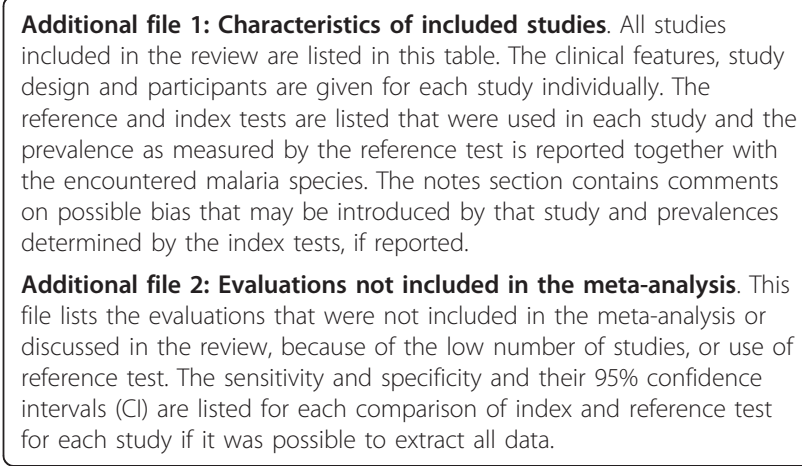

\section{List of abbreviations}

ANC: antenatal care; Cl: 95\% confidence interval; HRP2: histidine rich protein II; IPTp: intermittent preventive treatment; ITNs: insecticide treated nets; MiP: malaria in pregnancy; NCC: Nederlandse centrale catalogues (Dutch central catalogue); PCR: polymerase chain reaction; pLDH: Plasmodium lactate hydrogenase; PM: placental malaria; RDTs: rapid diagnostic tests; ROC: receiver operating characteristic; SROC plot: summary receiver operating characteristic plot; TDR: UNICEF/UNDP/World BankWHO Special Programme for research and Training in Tropical Diseases; WOS: Web of Science; QUADAS: Quality Assessment of Diagnostic Accuracy Studies.

\section{Acknowledgements}

We would like to thank Dr D Hamer for supplying additional data from one of the studies that was not reported in the published article about the study.

\section{Author details}

${ }^{1}$ Royal Tropical Institute/Koninklijk Instituut voor de Tropen (KIT), KIT Biomedical Research, Parasitology Unit, Meibergdreef 39, 1105 AZ Amsterdam, the Netherlands. ${ }^{2}$ Academic Medical Centre, Centre for Infection and Immunity, Meibergdreef 9, 1105 AZ, Amsterdam, the Netherlands. ${ }^{3}$ Academic Medical Centre, Department of Clinical Epidemiology, Biostatistics and Bioinformatics, Meibergdreef 9, 1105 AZ, Amsterdam, the Netherlands. ${ }^{4}$ Royal Tropical Institute/Koninklijk Instituut voor de Tropen (KIT), KIT Biomedical Research, Epidemiology Unit, Meibergdreef 39, 1105 AZ Amsterdam, the Netherlands. 


\section{Authors' contributions}

JK, PM and HS conceived the idea for this study. JK, PM, KB and ML designed the study. JK and EO performed the searches for studies, reviewed the retrieved studies and made the primary selection of eligible studies. Inclusion of the studies and methodological quality was assessed by JK and EO, and disagreement were resolved with PM and/or ML. Data was collected by JK and EO, and analysed by JK and ML. JK prepared the first draft of the paper and all authors contributed to the writing of the report and have reviewed and approved the final version.

\section{Competing interests}

The authors declare that they have no competing interests.

Received: 10 August 2011 Accepted: 28 October 2011

Published: 28 October 2011

\section{References}

1. Dellicour S, Tatem AJ, Guerra CA, Snow RW, ter Kuile FO: Quantifying the number of pregnancies at risk of malaria in 2007: a demographic study. PLoS Med 2010, 7:e1000221.

2. Desai M, ter Kuile FO, Nosten F, McGready R, Asamoa K, Brabin B, Newman RD: Epidemiology and burden of malaria in pregnancy. Lancet Infect Dis 2007, 7:93-104.

3. Nosten F, McGready R, Simpson JA, Thwai KL, Balkan S, Cho T, Hkirijaroen L, Looareesuwan S, White NJ: Effects of Plasmodium vivax malaria in pregnancy. Lancet 1999, 354:546-549.

4. Hartman TK, Rogerson SJ, Fischer PR: The impact of maternal malaria on newborns. Ann Trop Paediatr 2010, 30:271-282.

5. Malaria in Pregnancy, Roll Back Malaria infosheet. [http://www. rollbackmalaria.org].

6. Steketee RW, Nahlen BL, Parise ME, Menéndez C: The burden of malaria in pregnancy in malaria-endemic areas. Am J Trop Med Hyg 2001, 64:28-35.

7. McGready R, Davison BB, Stepniewska K, Cho T, Shee H, Brockman A, Udomsangpetch R, Looareesuwan S, White NJ, Meshnick SR, Nosten F: The effects of Plasmodium falciparum and $P$. vivax infections on placental histopathology in an area of low malaria transmission. Am J Trop Med Hyg 2004, 70:398-407.

8. Tagbor H, Bruce J, Agbo M, Greenwood B, Chandramohan D: Intermittent screening and treatment versus intermittent preventive treatment of malaria in pregnancy: a randomised controlled non-inferiority trial. PLoS One 2010, 5:e14425.

9. Miller LH, Baruch DI, Marsh K, Doumbo OK: The pathogenic basis of malaria. Nature 2002, 415:673-679.

10. Rogerson SJ, Hviid L, Duffy PE, Leke RF, Taylor DW: Malaria in pregnancy: pathogenesis and immunity. Lancet Infect Dis 2007, 7:105-117.

11. Uneke CJ: Diagnosis of Plasmodium falciparum malaria in pregnancy in sub-Saharan Africa: the challenges and public health implications. Parasitol Res 2008, 102:333-342.

12. Omo-Aghoja LO, Abe E, Feyi-Waboso P, Okonofua FE: The challenges of diagnosis and treatment of malaria in pregnancy in low resource settings. Acta Obstet Gynecol Scand 2008, 87:693-696.

13. Bulmer JN, Rasheed FN, Morrison L, Francis N, Greenwood BM: Placental malaria. II. A semi-quantitative investigation of the pathological features. Histopathology 1993, 22:219-225.

14. Bulmer JN, Rasheed FN, Francis N, Morrison L, Greenwood BM: Placental malaria. I. Pathological classification. Histopathology 1993, 22:211-218.

15. Uneke CJ: Impact of placental Plasmodium falciparum malaria on pregnancy and perinatal outcome in sub-Saharan Africa: I: introduction to placental malaria. Yale J Biol Med 2007, 80:39-50.

16. Shiff $C J$, Premji Z, Minjas JN: The rapid manual ParaSight-F test. A new diagnostic tool for Plasmodium falciparum infection. Trans R Soc Trop Med Hyg 1993, 87:646-648.

17. Piper R, Lebras J, Wentworth L, Hunt-Cooke A, Houze S, Chiodini P, Makler M: Immunocapture diagnostic assays for malaria using Plasmodium lactate dehydrogenase (pLDH). Am J Trop Med Hyg 1999, 60:109-118.

18. Abba K, Deeks JJ, Olliaro P, Naing CM, Jackson SM, Takwoingi Y, Donegan S, Garner P: Rapid diagnostic tests for diagnosing uncomplicated $P$. falciparum malaria in endemic countries. Cochrane Database Syst Rev 2011, CD008122
19. Chiodini PL, Bowers K, Jorgensen P, Barnwell JW, Grady KK, Luchavez J, Moody AH, Cenizal A, Bell D: The heat stability of Plasmodium lactate dehydrogenase-based and histidine-rich protein 2-based malaria rapid diagnostic tests. Trans R Soc Trop Med Hyg 2007, 101:331-337.

20. WHO: Malaria Rapid Diagnostic Test Performance - Results of WHO product testing of malaria RDTs: Round 1. 2008.

21. Lee N, Baker J, Andrews KT, Gatton ML, Bell D, Cheng Q, McCarthy J: Effect of sequence variation in Plasmodium falciparum histidine- rich protein 2 on binding of specific monoclonal antibodies: Implications for rapid diagnostic tests for malaria. J Clin Microbiol 2006, 44:2773-2778.

22. Leke RF, Djokam RR, Mbu R, Leke RJ, Fogako J, Megnekou R, Metenou S, Sama G, Zhou Y, Cadigan T, Parra M, Wallace Taylor D: Detection of the Plasmodium falciparum antigen histidine-rich protein 2 in blood of pregnant women: implications for diagnosing placental malaria. J Clin Microbiol 1999, 37:2992-2996.

23. Snounou G, Beck HP: The use of PCR genotyping in the assessment of recrudescence or reinfection after antimalarial drug treatment. Parasitol Today 1998, 14:462-467.

24. Felger I, Snounou G: Recommended Genotyping Procedures (RGPs) to identify parasite populations. 2008.

25. Lijmer JG, Mol BW, Heisterkamp S, Bonsel GJ, Prins MH, van der Meulen JH, Bossuyt PM: Empirical evidence of design-related bias in studies of diagnostic tests. JAMA 1999, 282:1061-1066.

26. Okoko BJ, Ota MO, Yamuah LK, Idiong D, Mkpanam SN, Avieka A, Banya WA, Osinusi K: Influence of placental malaria infection on foetal outcome in the Gambia: twenty years after lan Mcgregor. J Health Popul Nutr 2002, 20:4-11.

27. Brahmbhatt $H$, Sullivan $D$, Kigozi $G$, Askin $F$, Wabwire-Mangenm F, Serwadda D, Sewankambo N, Wawer M, Gray R: Association of HIV and malaria with mother-to-child transmission, birth outcomes, and child mortality. J Acquir Immune Defic Syndr 2008, 47:472-476.

28. Meuris $S$, Piko BB, Eerens $P$, Vanbellinghen AM, Dramaix M, Hennart P: Gestational malaria: assessment of its consequences on fetal growth. Am J Trop Med Hyg 1993, 48:603-609.

29. Cottrell G, Mary JY, Barro D, Cot M: Is malarial placental infection related to peripheral infection at any time of pregnancy? Am J Trop Med Hyg 2005, 73:1112-1118.

30. Roll Back Malaria Website. [http://www.rollbackmalaria.org].

31. WHO website - malaria. [http://www.who.int/topics/malaria/en/].

32. TDR website. [http://apps.who.int/tdr/].

33. Reference Manager Professional Edition version 12 (12). Thomson Reuters 2008.

34. Lauritsen JM, Bruus M: EpiData. A comprehensive tool for validated entry and documentation of data. (3). The EpiData Association, Odense Denmark; 2003.

35. Whiting P, Rutjes AW, Reitsma JB, Bossuyt PM, Kleijnen J: The development of QUADAS: a tool for the quality assessment of studies of diagnostic accuracy included in systematic reviews. BMC Med Res Methodol 2003, 3:25.

36. Review Manager (RevMan) (5.0). Copenhagen, The Nordic Cochrane Centre, The Cochrane Collaboration; 2008.

37. Harbord RM, Whiting P: metandi: Meta-analysis of diagnostic accuracy using hierarchical logistic regression. Stata J 2009, 9:211-229.

38. StataCorp: Stata Statistical Software: Release 9. (9.2). College Station, StataCorp LP; 2005.

39. Macaskill P, Gatsonis C, Deeks JJ, Harbord RM, Takwoingi Y: Chapter 10: Analyzing and presenting results. In Cochrane Handbook for systematic reviews of diagnostic test accuracy. version 1.0. Edited by: Deeks JJ, Bossuyt PM, Gatsonis C. The Cochrane Collaboration; 2010:

40. Adam I, Elbasit IE, Salih I, Elbashir MI: Submicroscopic Plasmodium falciparum infections during pregnancy, in an area of Sudan with a low intensity of malaria transmission. Ann Trop Med Parasitol 2005, 99:339-344.

41. Adegnika AA, Verweij JJ, Agnandji ST, Chai SK, Breitling LP, Ramharter M Frolich M, Issifou S, Kremsner PG, Yazdanbakhsh M: Microscopic and submicroscopic Plasmodium falciparum infection, but not inflammation caused by infection, is associated with low birth weight. Am J Trop Med Hyg 2006, 75:798-803.

42. Anchang-Kimbi JK, Achidi EA, Nkegoum B, Sverremark-Ekstrom E, TroyeBlomberg M: Diagnostic comparison of malaria infection in peripheral blood, placental blood and placental biopsies in Cameroonian parturient women. Malar J 2009, 8:126. 
43. Archibald HM: Influence of maternal malaria on newborn infants. Br Med J 1958, 2:1512-1514.

44. Bassiouny HK, Al-Maktari MT: Malaria in late pregnancy in Al Hodeidah Governorate, Yemen. East Mediterr Health J 2005, 11:606-617.

45. Bergstrom S, Fernandes A, Schwalbach J, Perez O, Miyar R: Materno-fetal transmission of pregnancy malaria: an immunoparasitological study on 202 parturients in Maputo. Gynecol Obstet Invest 1993, 35:103-107.

46. Clark HC: The diagnostic value of the placental blood film in aestivoautumnal malaria. J Exp Med 1915, 22:427-444.

47. Desowitz RS, Alpers MP: Placental Plasmodium falciparum parasitaemia in East Sepik (Papua New Guinea) women of different parity: the apparent absence of acute effects on mother and foetus. Ann Trop Med Parasitol 1992, 86:95-102.

48. Diallo S, Victorius A, Ndir O, Diouf F, Bah IB, Bah MD: Prevalence et évolution du paludisme congénital en zone urbaine: cas de la ville de Thies (Senegal). 1981.

49. Hamer DH, Singh MP, Wylie BJ, Yeboah-Antwi K, Tuchman J, Desai M, Udhayakumar V, Gupta P, Brooks Ml, Shukla MM, Awasthy K, Sabin L, MacLeod WB, Dash AP, Singh N: Burden of malaria in pregnancy in Jharkhand State, India. Malar J 2009, 8:210.

50. Ismail MR, Ordi J, Menéndez C, Ventura PJ, Aponte JJ, Kahigwa E, Hirt R, Cardesa A, Alonso PL: Placental pathology in malaria: a histological, immunohistochemical, and quantitative study. Hum Pathol 2000, 31:85-93.

51. Kalanda BF, Verhoeff FH, Chimsuku L, Harper G, Brabin BJ: Adverse birth outcomes in a malarious area. Epidemiol Infect 2006, 134:659-666.

52. Kassberger F, Birkenmaier A, Khattab A, Kremsner PG, Klinkert MQ: PCR typing of Plasmodium falciparum in matched peripheral, placental and umbilical cord blood. Parasitol Res 2002, 88:1073-1079.

53. Kasumba IN, Nalunkuma AJ, Mujuzi G, Kitaka FS, Byaruhanga R, Okong P, Egwang TG: Low birthweight associated with maternal anaemia and Plasmodium falciparum infection during pregnancy, in a peri-urban/ urban area of low endemicity in Uganda. Ann Trop Med Parasitol 2000, 94:7-13.

54. Kilian AH, Kabagambe G, Byamukama W, Langi P, Weis P, von SF: Application of the ParaSight- $F$ dipstick test for malaria diagnosis in a district control program. Acta Trop 1999, 72:281-293.

55. Leopardi O, Naughten W, Salvia L, Colecchia M, Matteelli A, Zucchi A, Shein A, Muchi JA, Carosi G, Ghione M: Malaric placentas. A quantitative study and clinico-pathological correlations. Pathol Res Pract 1996, 192:892-898

56. Lukuka KA, Fumie OS, Mulumbu MR, Lokombe BJ, Muyembe TJ: Malaria prevalence at delivery in four maternity hospitals of Kinshasa City, Democratic Republic of Congo. Bull Soc Pathol Exot 2006, 99:200-201.

57. Malhotra I, Dent A, Mungai P, Muchiri E, King CL: Real-time quantitative PCR for determining the burden of Plasmodium falciparum parasites during pregnancy and infancy. J Clin Microbiol 2005, 43:3630-3635.

58. Mankhambo L, Kanjala M, Rudman S, Lema VM, Rogerson SJ: Evaluation of the OptiMAL rapid antigen test and species-specific PCR to detect placental Plasmodium falciparum infection at delivery. J Clin Microbiol 2002, 40:155-158.

59. Mayengue PI, Rieth H, Khattab A, Issifou S, Kremsner PG, Klinkert MQ Ntoumi F: Submicroscopic Plasmodium falciparum infections and multiplicity of infection in matched peripheral, placental and umbilical cord blood samples from Gabonese women. Trop Med Int Health 2004, 9:949-958.

60. Mayor A, Serra-Casas E, Bardaji A, Sanz S, Puyol L, Cistero P, Sigauque B, Mandomando I, Aponte JJ, Alonso PL, Menéndez : Sub-microscopic infections and long-term recrudescence of Plasmodium falciparum in Mozambican pregnant women. Malar J 2009, 8:9.

61. Menéndez C, Bardaji A, Sigauque B, Romagosa C, Sanz S, Serra-Casas E, Macete E, Berenguera A, David C, Dobano C, Naniche D, Mayor A, Ordi J, Mandomando I, Aponte JJ, Mabunda S, Alonso PL: A randomized placebocontrolled trial of intermittent preventive treatment in pregnant women in the context of insecticide treated nets delivered through the antenatal clinic. PLoS One 2008, 3:e1934.

62. Minang JT, Gyan BA, Anchang JK, Troye-Blomberg M, Perlmann H, Achidi EA: Haptoglobin phenotypes and malaria infection in pregnant women at delivery in western Cameroon. Acta Trop 2004, 90:107-114.
63. Mockenhaupt FP, Rong B, Till H, Eggelte TA, Beck S, Gyasi-Sarpong C, Thompson WN, Bienzle U: Submicroscopic Plasmodium falciparum infections in pregnancy in Ghana. Trop Med Int Health 2000, 5:167-173.

64. Mockenhaupt FP, Bedu-Addo G, von GC, Boye R, Fricke K, Hannibal I, Karakaya F, Schaller M, Ulmen U, Acquah PA, et al: Detection and clinical manifestation of placental malaria in southern Ghana. Malar J 2006, 5:119

65. Mokuolu OA, Falade CO, Orogade AA, Okafor HU, Adedoyin OT, Oguonu TA, Dada-Adegbola HO, Oguntayo OA, Ernest SK, Hamer DH, et al: Malaria at parturition in Nigeria: current status and delivery outcome. Infect Dis Obstet Gynecol 2009, 2009:473971.

66. Mukhtar MY, Lesi FE, Iroha EU, Egri-Okwaji MT, Mafe AG: Congenital malaria among inborn babies at a tertiary centre in Lagos, Nigeria. J Trop Pediatr 2006, 52:19-23.

67. Nyirjesy P, Kavasya T, Axelrod P, Fischer PR: Malaria during pregnancy: neonatal morbidity and mortality and the efficacy of chloroquine chemoprophylaxis. Clin Infect Dis 1993, 16:127-132.

68. Peel $E$, Van Hoof L: La paludisme à la maternité indigène de Léopoldville. Ann Soc Belg Med Trop 1948, 28:413-420.

69. Rogerson SJ, Mkundika P, Kanjala MK: Diagnosis of Plasmodium falciparum malaria at delivery: comparison of blood film preparation methods and of blood films with histology. J Clin Microbiol 2003, 41:1370-1374.

70. Sarr D, Marrama L, Gaye A, Dangou JM, Niang M, Mercereau-Puijalon O, Lehesran JY, Jambou R: High prevalence of placental malaria and low birth weight in Sahelian periurban area. Am J Trop Med Hyg 2006, 75:171-177.

71. Saute F, Menéndez C, Mayor A, Aponte J, Gomez-Olive X, Dgedge M, Alonso P: Malaria in pregnancy in rural Mozambique: the role of parity, submicroscopic and multiple Plasmodium falciparum infections. Trop Med Int Health 2002, 7:19-28.

72. Schwetz J, Peel : Congenital malaria and placental infections amongst the negroes of central Africa. Trans R Soc Trop Med Hyg 1934, 28.

73. Shulman CE, Marshall T, Dorman EK, Bulmer JN, Cutts F, Peshu N, Marsh K. Malaria in pregnancy: adverse effects on haemoglobin levels and birthweight in primigravidae and multigravidae. Trop Med Int Health 2001, 6:770-778.

74. Singer LM, Newman RD, Diarra A, Moran AC, Huber CS, Stennies G, Sirima SB, Konate A, Yameogo M, Sawadogo R, Barnwell JW, Parise ME: Evaluation of a malaria rapid diagnostic test for assessing the burden of malaria during pregnancy. Am J Trop Med Hyg 2004, 70:481-485.

75. Singh N, Saxena A, Awadhia SB, Shrivastava R, Singh MP: Evaluation of a rapid diagnostic test for assessing the burden of malaria at delivery in India. Am J Trop Med Hyg 2005, 73:855-858.

76. Singh PP, Ahmed R, Singh MP, Terlouw DJ, ter Kuile FO, Desai MR, Udhayakumar V, Dash AP, Singh N: Evaluation of the new malaria rapid diagnostic test First Response (R) Pf/Pv, when used as a screening tool for malaria during pregnancy in central India. Am J Trop Med Hyg 2007, 77:341.

77. Sowunmi $A$, llesanmi $A O$, Akindele JA, Abohweyere AEJ, Fawole AO, Falade CO, Oduola AMJ: Placental falciparum infection and outcome of pregnancy in Nigerian mothers from an endemic area. J Obstet Gynaecol 1996, 16:211-216.

78. Sullivan AD, Nyirenda T, Cullinan T, Taylor T, Lau A, Meshnick SR: Placental haemozoin and malaria in pregnancy. Placenta 2000, 21:417-421.

79. Tagbor H, Bruce J, Browne E, Greenwood B, Chandramohan D: Performance of the OptiMAL dipstick in the diagnosis of malaria infection in pregnancy. Ther Clin Risk Manag 2008, 4:631-636.

80. Tako EA, Zhou A, Lohoue J, Leke R, Taylor DW, Leke RF: Risk factors for placental malaria and its effect on pregnancy outcome in Yaounde, Cameroon. Am J Trop Med Hyg 2005, 72:236-242.

81. van Dongen PW, van't Hof MA: Sickle cell trait, malaria and anaemia in Zambian pregnant women. Med J Zambia 1982, 16:58-62.

82. van Eijk AM, Ayisi JG, ter Kuile FO, Misore AO, Otieno JA, Rosen DH, Kager PA, Steketee RW, Nahlen BL: Risk factors for malaria in pregnancy in an urban and peri-urban population in western Kenya. Trans $R$ Soc Trop Med Hyg 2002, 96:586-592.

83. VanderJagt TA, Ikeh El, Ujah IO, Belmonte J, Glew RH, Vanderjagt DJ: Comparison of the OptiMAL rapid test and microscopy for detection of malaria in pregnant women in Nigeria. Trop Med Int Health 2005, 10:39-41. 
84. Walker-Abbey A, Djokam RR, Eno A, Leke RF, Titanji VP, Fogako J, Sama G, Thuita LH, Beardslee E, Snounou G, Zhou A, Wallace Taylor D: Malaria in pregnant Cameroonian women: the effect of age and gravidity on submicroscopic and mixed-species infections and multiple parasite genotypes. Am J Trop Med Hyg 2005, 72:229-235.

85. Albiti AH, Adam I, Ghouth AS: Placental malaria, anaemia and low birthweight in Yemen. Trans R Soc Trop Med Hyg 2010, 104:191-194.

86. Bako BG, Audu BM, Geidam AD, Kullima AA, Ashiru GM, Malah MB, Ngadda HA, Musa AB: Prevalence, risk factors and effects of placental malaria in the UMTH, Maiduguri, North-eastern, Nigeria: a cross-sectional study. J Obstet Gynaecol 2009, 29:307-310

87. Bouyou-Akotet MK, Nzenze-Afene S, Ngoungou EB, Kendjo E, OwonoMedang M, Lekana-Douki JB, Obono-Obiang G, Mounanga M, Kombila M: Burden of malaria during pregnancy at the time of IPTp/SP implementation in Gabon. Am J Trop Med Hyg 2010, 82:202-209.

88. Carmona-Fonseca J, Gallego AF, Florez EA, Garcia OMA, Buitrago AM: Now ICT malaria Pf/Pv frente a microscopia (gota gruesa-extendido) para diagnostico de malaria en Uraba (Colombia). latreia 2010, 23.

89. Falade $\mathrm{CO}$, Tongo $\mathrm{OO}$, Ogunkunle $\mathrm{OO}$, Orimadegun AE: Effects of malaria in pregnancy on newborn anthropometry. J Infect Dev Ctries 2010, 4:448-453.

90. Newman PM, Wanzira H, Tumwine G, Arinaitwe E, Waldman S, Achan J, Havlir D, Rosenthal PJ, Dorsey G, Clark TD, Cohan D: Placental malaria among HIV-infected and uninfected women receiving anti-folates in a high transmission area of Uganda. Malar J 2009, 8:254.

91. Omer S, Khalil E, Ali H, Sharief A: Submicroscopic and multiple Plasmodium falciparum infections in pregnant Sudanese women. North Am J Med Sci 2011, 3:137-141.

92. Piola P, Nabasumba C, Turyakira E, Dhorda M, Lindegardh N, Nyehangane D, Snounou G, Ashley EA, McGready R, Nosten F, Guerin PJ: Efficacy and safety of artemether-lumefantrine compared with quinine in pregnant women with uncomplicated Plasmodium falciparum malaria: an open-label, randomised, non-inferiority trial. Lancet Infect Dis 2010, 10:762-769.

93. Rantala AM, Taylor SM, Trottman PA, Luntamo M, Mbewe B, Maleta K, Kulmala T, Ashorn P, Meshnick SR: Comparison of real-time PCR and microscopy for malaria parasite detection in Malawian pregnant women. Malar J 2010, 9:269.

94. Taylor SM, Juliano JJ, Trottman PA, Griffin JB, Landis SH, Kitsa P, Tshefu AK, Meshnick SR: High-throughput pooling and real-time PCR-based strategy for malaria detection. J Clin Microbiol 2010, 48:512-519.

95. Arango $E$, Maestre $A$, Carmona-Fonseca J: Effecto de la infección submicroscópica o poloclonal de Plasmodium falciparum sobre la madre y el producto de la gestación. Revisión sistemàtica. Rev Bras Epidemiol 2010, 13:373-386.

doi:10.1186/1475-2875-10-321

Cite this article as: Kattenberg et al:: Systematic review and metaanalysis: rapid diagnostic tests versus placental histology, microscopy and PCR for malaria in pregnant women. Malaria Journal 2011 10:321.

\section{Submit your next manuscript to BioMed Central and take full advantage of:}

- Convenient online submission

- Thorough peer review

- No space constraints or color figure charges

- Immediate publication on acceptance

- Inclusion in PubMed, CAS, Scopus and Google Scholar

- Research which is freely available for redistribution 